University of Nebraska - Lincoln

DigitalCommons@University of Nebraska - Lincoln

Hydrogeophysical Methods for Analyzing Aquifer Storage and Recovery Systems

\author{
Burke J. Minsley \\ U.S. Geological Survey, bminsley@usgs.gov \\ Jonathan Ajo-Franklin \\ Lawrence Berkeley National Laboratory \\ Amitabha Mukhopadhyay \\ Kuwait Institute for Scientific Research \\ Frank Dale Morgan \\ Massachusetts Institute of Technology
}

Follow this and additional works at: https://digitalcommons.unl.edu/usgsstaffpub

Part of the Earth Sciences Commons

Minsley, Burke J.; Ajo-Franklin, Jonathan; Mukhopadhyay, Amitabha; and Morgan, Frank Dale, "Hydrogeophysical Methods for Analyzing Aquifer Storage and Recovery Systems" (2010). USGS Staff -Published Research. 516.

https://digitalcommons.unl.edu/usgsstaffpub/516

This Article is brought to you for free and open access by the US Geological Survey at DigitalCommons@University of Nebraska - Lincoln. It has been accepted for inclusion in USGS Staff -- Published Research by an authorized administrator of DigitalCommons@University of Nebraska - Lincoln. 


\title{
Hydrogeophysical Methods for Analyzing Aquifer Storage and Recovery Systems
}

\author{
by Burke J. Minsley ${ }^{1,2}$, Jonathan Ajo-Franklin ${ }^{3}$, Amitabha Mukhopadhyay ${ }^{4}$, and Frank Dale Morgan ${ }^{2}$
}

\begin{abstract}
Hydrogeophysical methods are presented that support the siting and monitoring of aquifer storage and recovery (ASR) systems. These methods are presented as numerical simulations in the context of a proposed ASR experiment in Kuwait, although the techniques are applicable to numerous ASR projects. Bulk geophysical properties are calculated directly from ASR flow and solute transport simulations using standard petrophysical relationships and are used to simulate the dynamic geophysical response to ASR. This strategy provides a quantitative framework for determining site-specific geophysical methods and data acquisition geometries that can provide the most useful information about the ASR implementation. An axisymmetric, coupled fluid flow and solute transport model simulates injection, storage, and withdrawal of fresh water (salinity $\sim 500 \mathrm{ppm}$ ) into the Dammam aquifer, a tertiary carbonate formation with native salinity approximately $6000 \mathrm{ppm}$. Sensitivity of the flow simulations to the correlation length of aquifer heterogeneity, aquifer dispersivity, and hydraulic permeability of the confining layer are investigated. The geophysical response using electrical resistivity, time-domain electromagnetic (TEM), and seismic methods is computed at regular intervals during the ASR simulation to investigate the sensitivity of these different techniques to changes in subsurface properties. For the electrical and electromagnetic methods, fluid electric conductivity is derived from the modeled salinity and is combined with an assumed porosity model to compute a bulk electrical resistivity structure. The seismic response is computed from the porosity model and changes in effective stress due to fluid pressure variations during injection/recovery, while changes in fluid properties are introduced through Gassmann fluid substitution.
\end{abstract}

\section{Introduction}

Efficient use of water resources is becoming increasingly important throughout the world due to rising demand, particularly in locations where resources are scarce and/or expensive to produce. Aquifer storage and

${ }^{1}$ Corresponding author: Currently at U.S. Geological Survey, Denver Federal Center, MS964, Denver, C0 80225; (303) 236-5718; fax: (303) 236-1425; bminsley@usgs.gov

${ }^{2}$ Department of Earth, Atmospheric, and Planetary Sciences, Massachusetts Institute of Technology, 77 Massachusetts Avenue, 54-1821 Cambridge, MA 02139.

${ }^{3}$ Lawrence Berkeley National Laboratory, 1 Cyclotron Road, MS90-1116 Berkeley, CA 94720.

${ }^{4}$ Kuwait Institute for Scientific Research, P.0. Box 24885, 13109 Safat, Kuwait.

Received July 2009, accepted December 2009.

Copyright (C) 2010 The Author(s)

Journal compilation @ 2010 National Ground Water Association. doi: $10.1111 /$ j.1745-6584.2010.00676.x recovery (ASR) is one method that is gaining attention as a means of storing excess water during periods when seasonal demand is less than capacity, or in the case of an emergency interruption in supply (e.g., Pyne 1995). ASR involves injecting surplus water into an existing subsurface aquifer, with the intention of withdrawing for use later when demand is high. This has certain advantages over surface storage in tanks or reservoirs, such as reduced land use, decreased risk of contamination or tampering, and reduced loss to evaporation.

One challenge, however, is to ensure that a significant portion of the stored water will be recoverable in the future. This involves understanding the dynamic hydrogeologic response of the aquifer system to artificial groundwater recharge and recovery so that wells can be optimally sited and operated. In addition to hydrologic and geochemical data collected in observation wells, geophysical methods can provide valuable information 
about subsurface structures and physical properties that will be useful in both the planning and monitoring phases of an ASR program. Geophysical methods have been used for many years in a variety of hydrogeologic applications (Rubin and Hubbard 2005), although they have not been widely applied to ASR projects. For example, Bevc and Morrison (1991) used DC resistivity to monitor a salt water injection experiment, Singha et al. (2007) used geoelectric measurements to study complex transport behavior during an ASR experiment in a fractured aquifer, Darnet et al. (2004) discussed the origin of self-potential signals during injection into a geothermal reservoir, Davis et al. (2008) used time-lapse microgravity surveys to monitor aquifer storage in a coal mine, Miller et al. (2006) investigated the feasibility of using time-lapse controlled source electromagnetic methods to monitor an aquifer storage experiment, and Parra et al. (2006) used seismic data to characterize subsurface aquifer properties to guide the placement of future ASR wells.

In this study, we evaluate the utility of several geophysical methods in the context of a proposed ASR study in Kuwait (Mukhopadhyay et al. 1998). Kuwait is an arid nation with an average annual rainfall of $110 \mathrm{~mm}$ and negligible natural recharge from the ground surface (Mukhopadhyay et al. 1996). The average annual fresh water consumption rate in Kuwait for the year 2004 was $473 \mathrm{~L} /$ day/capita, with a total population of nearly three million, met almost exclusively by desalination (Al-Otaibi and Mukhopadhyay 2005). An additional 150 L/day/capita of brackish groundwater (3000 to $5000 \mathrm{mg} / \mathrm{L}$ ) is used primarily for irrigation and landscaping, which is putting significant stress on the groundwater reservoirs (Al-Otaibi and Mukhopadhyay 2005; Al-Senafy and Abraham 2004). One possible strategy to mitigate this problem is to use treated waste water that is being processed at a reverse osmosis plant for irrigation and agricultural use. The output of treated waste water was approximately 320,000 $\mathrm{m}^{3} / \mathrm{d}$ in 2004 and is expected to double by 2025 (AlOtaibi and Mukhopadhyay 2005). Excess treated waste water can also be used for artificial groundwater recharge. Because of seasonal variability in demand, there was an average of approximately $115,000 \mathrm{~m}^{3} / \mathrm{d}$ in 2004 of excess capacity fresh water from desalination that could also be made available for artificial recharge.

Our goal is to understand the sensitivity of various geophysical techniques to the natural subsurface hydrogeologic structure as well as changes caused by injection or withdrawal of water into a confined aquifer, with the plan that the most useful method(s) will be used during future field experiments. The finite-element package COMSOL Multiphysics is used to simulate the ASR phases using a coupled fluid flow and solute transport model. Existing hydrogeologic information about the area (Al-Awadi et al. 1998; Mukhopadhyay et al. 1996), based primarily on information obtained from the many wells used for water and oil production in Kuwait since the 1960s (Figure 1), is incorporated into the flow model. At any stage in the simulation, the geophysical response can be computed from the relevant hydrogeologic parameters such as pressure, salinity, density, and porosity. One benefit for both the numerical and field experiments is that time-lapse data can be collected. Differencing the preinjection and postinjection datasets helps to isolate the effect of the injection and remove background structure.

In this study, the primary geophysical response to the ASR simulation is due to changes in the electrical resistivity structure, which is determined from variations in aquifer salinity and the static porosity structure using Archie's law. We therefore focus on two methods that are sensitive to the subsurface electrical properties, DC resistivity and time-domain electromagnetics (TEM). Other electromagnetic methods, such as controlled source audio magnetotellurics (CSAMT), may also prove useful but are not investigated here. Additionally, we investigate the seismic response to the injection experiment, which is primarily sensitive to changes in effective stress due to pore pressure changes, but is also influenced to a small extent by changes in fluid seismic velocity due to variations in salinity.

Other geophysical techniques determined to have very limited sensitivity to this particular ASR case study and are therefore not considered in detail, include selfpotentials and gravity. The self-potential response is very small (well below typical noise of a few millivolts) due to the deep injection in this case study. Variations in gravity are far too small to be detectable in this study where fluid is injected into a confined aquifer and density changes are solely due to salinity changes rather than the case of fluids displacing air in an unconfined aquifer. Methods that are sensitive to surface deformation, such as global positioning system (GPS) or interferometric synthetic aperture radar (InSAR) monitoring, have been applied to aquifer compaction problems related to hydrocarbon production (e.g., Nagel 2001) and may prove useful in future studies of large-scale ASR experiments.

\section{Site Hydrogeology and Aquifer Model \\ Background Hydrogeology}

The general stratigraphy and hydrogeologic units for the tertiary sedimentary sequence in Kuwait are shown in Figure 2. In Kuwait, useable groundwater (salinity less than $5000 \mathrm{mg} / \mathrm{L}$ ) occurs in the aquifers of the Dammam formation and the Kuwait group. The recharge in these aquifers from rainfall mainly takes place outside the territory of Kuwait in Saudi Arabia and Iraq. The regional setting suggests that the groundwater flows from these recharge zones toward the north and east and becomes more saline as it reaches the discharge zone along the coast of the Arabian Gulf. The Gulf is underlain by a static body of very saline water (more than 150,000 mg/L), and Kuwait is situated in the northwestern corner of this discharge zone.

Because of the higher salinity (a minimum of $4000 \mathrm{mg} / \mathrm{L}$ ), hydrogen sulfide content and low productivity (transmissivity in the upper part of the aquifer around $40 \mathrm{~m}^{2} / \mathrm{d}$ in the southwestern part of the country), the Umm 


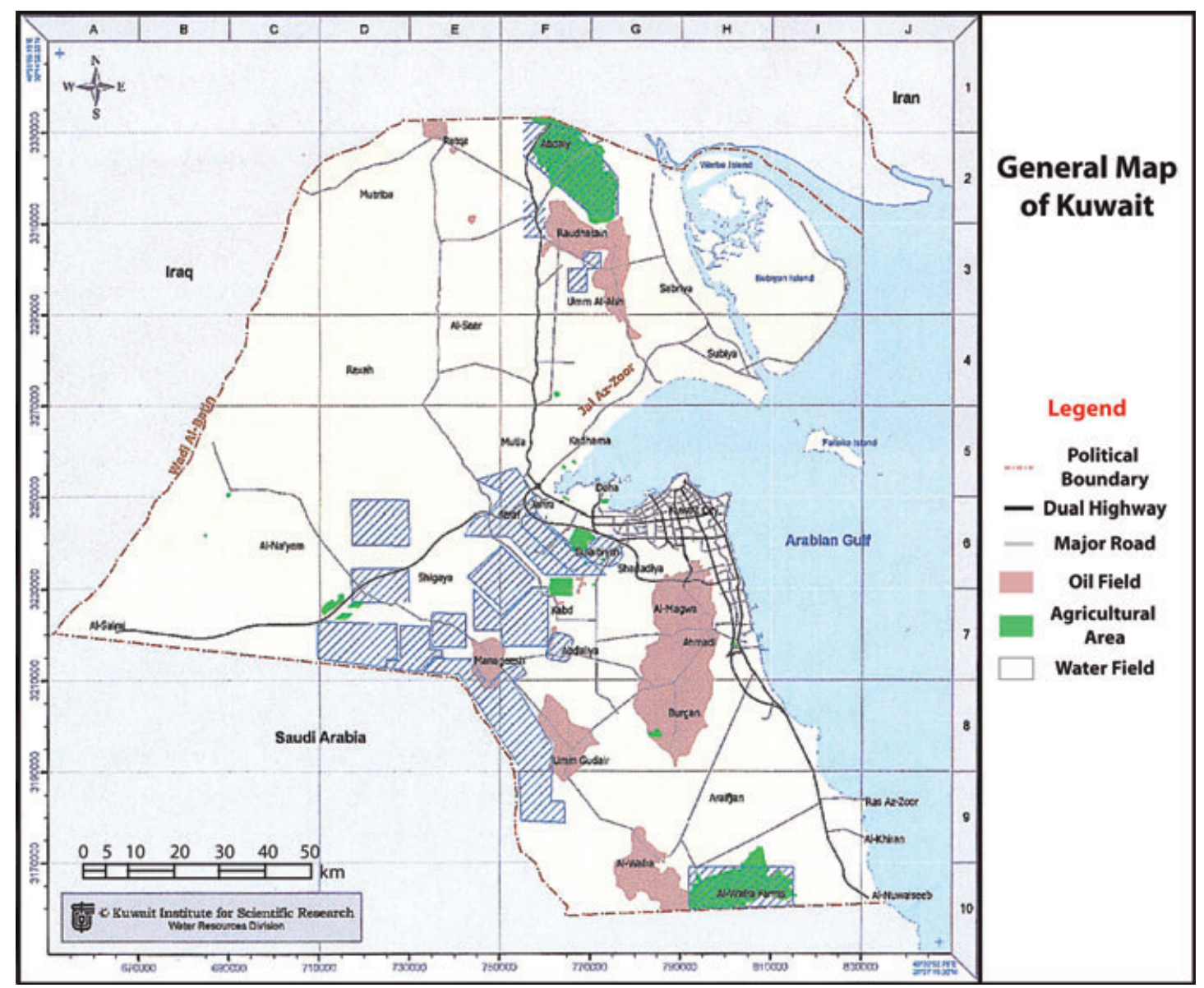

Figure 1. Map of Kuwait denoting water fields (blue), oil fields (brown), and agricultural areas (green).

Er-Radhuma aquifer is not exploited in Kuwait (Omar et al. 1981). The anhydritic Rus formation and the basal shales of the lower members of the Dammam formation act as an aquitard in Kuwait, separating the underlying Umm Er-Radhuma aquifer from the Dammam aquifer.

The lithology, petrophysical characteristics such as porosity and permeability, and distribution of lost circulation zones in existing wells suggest that the upper member, and possibly the middle member constitute the main aquifers in the Dammam formation (Al-Awadi and Mukhopadhyay 1995). Because of its karstic nature, the transmissivity in the Dammam formation is variable, especially in the south and southwestern parts of Kuwait, but shows a general decreasing trend toward the northeast. The silicified topmost part of the Dammam formation, in conjunction with the basal shaley/clayey layers of the Kuwait group, forms an aquitard that separates the Dammam aquifer from the overlying Kuwait group aquifer, although hydraulic continuity is possibly maintained in some locations through fractures that are present in the top part of the Dammam formation.

The undifferentiated Fars and the Ghar formations of Kuwait constitute the main Kuwait group aquifer. A sandy-shaley unit that acts as an aquitard divides this aquifer into upper and lower units. The lower aquifer is semiconfined in nature, and the upper aquifer is unconfined in the central and southern parts of the country. The total transmissivity of the Kuwait group aquifer increases from southwest (less than or equal to $10 \mathrm{~m}^{2} / \mathrm{d}$ ) to northeast (greater than or equal to $1500 \mathrm{~m}^{2} / \mathrm{d}$ ), corresponding with an increase in saturated thickness in this direction (from 0 to $400 \mathrm{~m}$ ).

\section{Synthetic Aquifer Model Definition}

We define a synthetic aquifer model, illustrated in Figure 3, that is based on the relevant hydrogeologic units discussed in the preceding paragraphs, with aquifer parameters taken primarily from Mukhopadhyay and $\mathrm{Al}$ Otaibi (2002). This model is used to simulate the dynamic hydrogeologic response of ASR, which is subsequently used to compute the geophysical response at various stages during an ASR experiment. For computational efficiency, we first consider injection and recovery using a single well in an axisymmetric model, where the symmetry axis lies at $0 \mathrm{~m}$ at the left of Figure 3 . Although the axisymmetric model is somewhat simplified and does not account for the influence of structural topography or regional groundwater flow, it provides a useful step toward understanding the general hydrogeophysical characteristics of the ASR experiment. Future modeling experiments will focus on a three-dimensional (3D) geometry with multiple injection and recovery wells to 


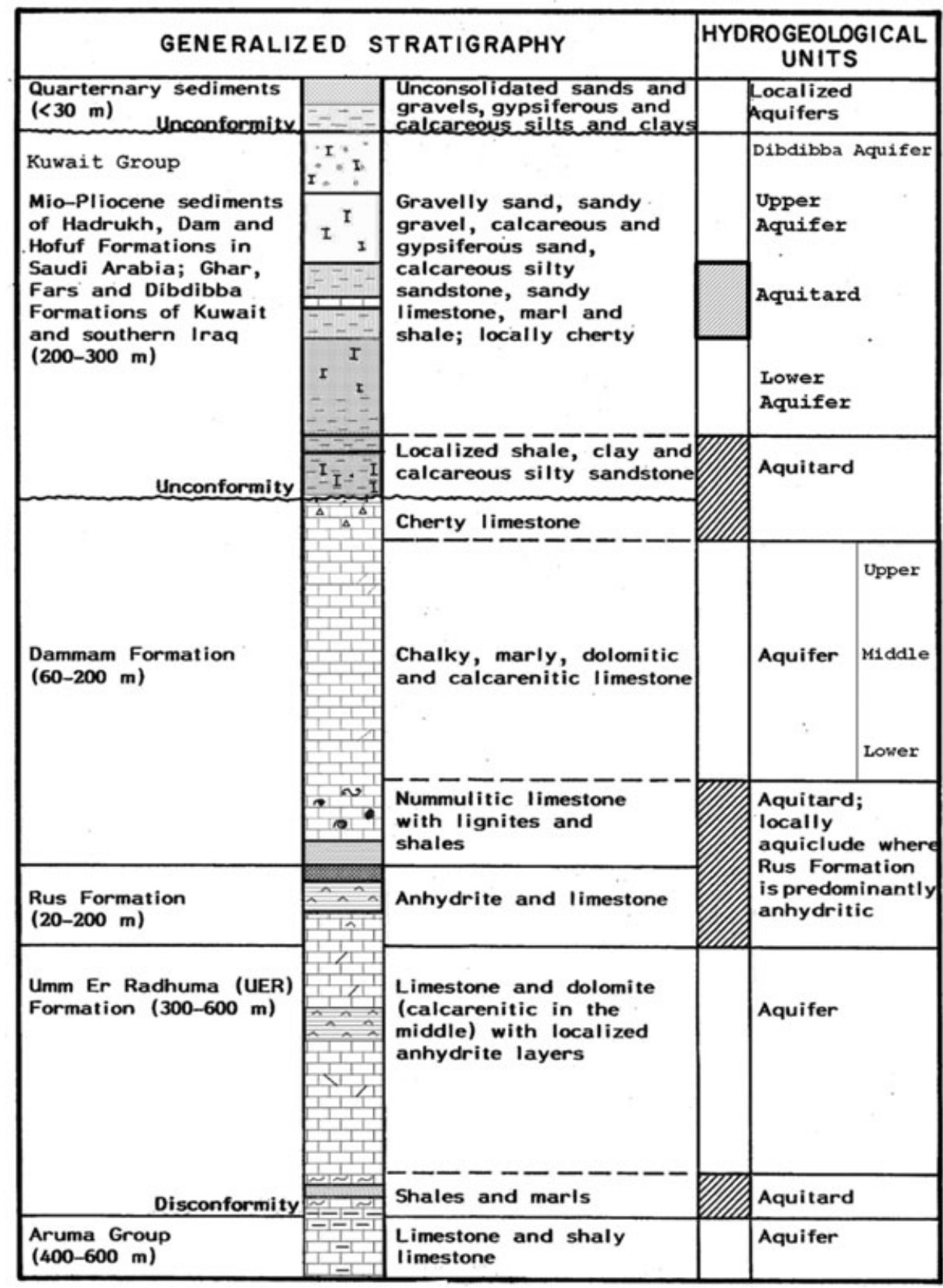

Figure 2. General Kuwait stratigraphy and hydrogeologic units (adapted from Mukhopadhyay et al. 1996).

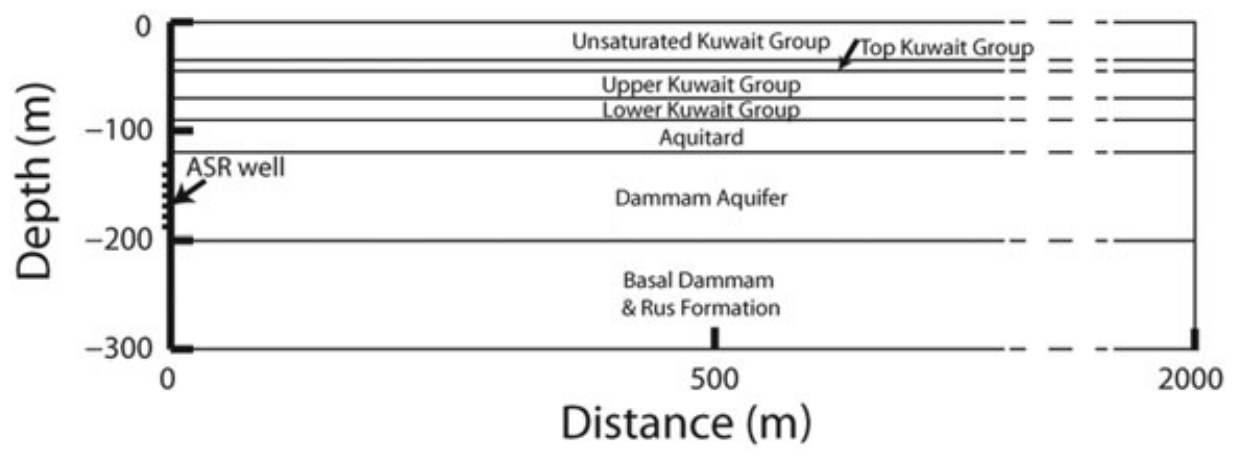

Figure 3. Synthetic aquifer model used for hydrogeologic and geophysical modeling (based on Mukhopadhyay and Al-Otaibi 2002). 
simulate the large-scale implementation of ASR that has been proposed in Kuwait (Mukhopadhyay et al. 1998).

The aquifer parameters for our baseline model are taken from the "reference run" in Mukhopadhyay and AlOtaibi (2002) and are summarized in Table 1. Variations on this baseline model can be used to understand the sensitivity of the hydrogeophysical response to different parameters. In this study, we investigate the effects of (1) varying the length of the screened portion of the ASR well, (2) using a heterogeneous hydraulic permeability model within the Dammam aquifer, which is where most of the flow occurs, (3) varying the vertical hydraulic permeability of the aquitard, and (4) varying the dispersivity within the Dammam aquifer. Mukhopadhyay and Al-Otaibi (2002) suggest that the latter two effects have significant control on the subsurface flow behavior.

\section{Coupled Fluid Flow and Solute Transport Modeling Modeling Equations}

Numerical simulation of an ASR experiment requires tracking the injection of fresh water (low salinity) into a (typically) more saline aquifer, followed by storage and recovery phases. Repeated injection-recovery cycles are sometimes used to create a buffer between the natural aquifer and the injected water (Pyne 1995). Modeling the ASR process can be accomplished by solving the coupled fluid mass balance and solute transport equations (Ackerer et al. 1999; Bear 1972), where fluid salinity is the state variable within the solute transport equation. The fluid mass balance is given by:

$$
\rho S \frac{\partial P}{\partial t}+\phi \frac{\partial \rho}{\partial C} \frac{\partial C}{\partial t}+\nabla(\rho \boldsymbol{q})=\rho Q
$$

where $P(\mathrm{~Pa})$ is the state variable that represents hydraulic pressure, $\rho$ is the fluid density $\left(\mathrm{kg} / \mathrm{m}^{3}\right), S$ is the specific storativity $(1 / \mathrm{Pa}), \phi$ is the porosity $(\cdot), C$ is the fluid salinity $\left(\mathrm{kg} / \mathrm{m}^{3}\right), Q$ represents a fluid source or sink $(1 / \mathrm{s})$, and $\boldsymbol{q}$ is the Darcy flux $(\mathrm{m} / \mathrm{s})$ such that:

$$
\boldsymbol{q}=-\frac{\boldsymbol{k}}{\mu} \nabla(P+\rho g z)
$$

In Equation 2, $\boldsymbol{k}$ is the hydraulic permeability tensor $\left(\mathrm{m}^{2}\right), \mu$ is the fluid viscosity $(\mathrm{Pa} \mathrm{s}), g$ is the gravitational acceleration $\left(\mathrm{m} / \mathrm{s}^{2}\right)$, and $z$ is elevation $(\mathrm{m})$. Solute transport is governed by an advection-dispersion equation:

$$
\phi \frac{\partial C}{\partial t}+\nabla(-\phi \boldsymbol{D} \nabla C+\boldsymbol{q} C)=0
$$

where the fluid salinity, $C$, is the state variable and $\boldsymbol{D}$ is the dispersion tensor,

$$
\boldsymbol{D}=D_{\mathrm{m}} \boldsymbol{I}+\left(\alpha_{\mathrm{L}}-\alpha_{\mathrm{T}}\right) \frac{\boldsymbol{q} \boldsymbol{q}^{\mathrm{T}}}{|\boldsymbol{q}|}+\alpha_{\mathrm{T}}|\boldsymbol{q}| \boldsymbol{I}
$$

\begin{tabular}{|c|c|c|c|}
\hline 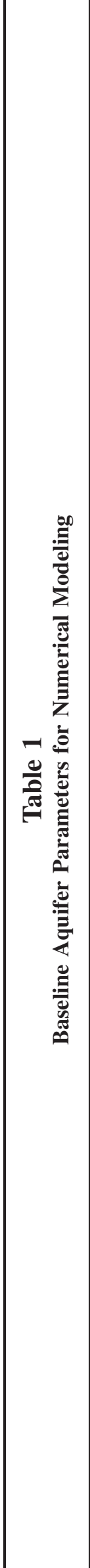 & 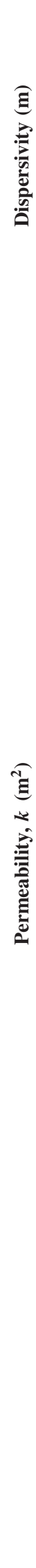 & 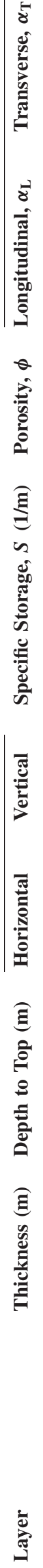 & 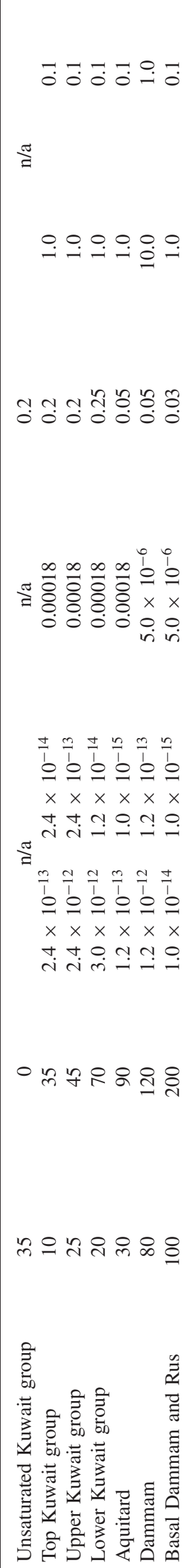 \\
\hline
\end{tabular}

The dispersion tensor consists of both molecular diffusion, $D_{\mathrm{m}}\left(\mathrm{m}^{2} / \mathrm{s}\right)$, and mechanical dispersion that is 
controlled by the longitudinal and transverse dispersivity, $\alpha_{\mathrm{L}, \mathrm{T}}(\mathrm{m})$, in conjunction with the flux, and $\boldsymbol{I}$ is the identity matrix. The coupled system of equations is solved using the COMSOL Multiphysics finite-element software package.

Equations 1 and 3 are strongly two-way coupled, such that there are multiple feedbacks between the fluid flow and solute transport equations. The most direct coupling occurs through the fact that the Darcy flux, $\boldsymbol{q}$, appears in the advective term in Equation 3 as well as the dispersion tensor in Equation 4; therefore, solute transport is strongly controlled by the fluid flow field induced by pumping at the well. Coupling back to the fluid mass transport equation occurs because of the dependence of fluid density and viscosity on salinity. Buoyancy effects due to the difference in density between injected and natural aquifer fluids are important for ASR projects, particularly for strong density contrasts and/or long storage times (e.g., Ward et al. 2007) The second term in Equation 1 describes temporal changes in density that are due to the rate of change in salinity. Values for fluid density and viscosity are updated continuously as a function of the current temperature, pressure, and salinity based on the relationships given by Batzle and Wang (1992), although a constant reference temperature of $15{ }^{\circ} \mathrm{C}$ is used throughout this study. That is, $\rho=\rho(P, C, T)$ and $\mu=\mu(P, C, T)$. Temperature-related effects are expected to be small compared with those due to changes in salinity, which justifies the use of a constant temperature for this study. An additional set of equations similar to Equations 3 and 4 can be added to the coupled system to model the thermal behavior of the model and provide temperature feedbacks through changes in density and viscosity.

\section{Initial and Boundary Conditions}

This coupled system of equations is solved using the geometry shown in Figure 3, with the exception of the uppermost unsaturated layer where there is no flow. Initial conditions for pressure and salinity are given as a function of depth based on prior regional information. The initial pressure in the Kuwait group corresponds to a piezometric level of $-35 \mathrm{~m}$ (top of the saturated zone), whereas the initial pressure in the confined Dammam aquifer and Rus formation corresponds to slightly higher piezometric level of $-28 \mathrm{~m}$. A linear gradient in head is prescribed within the aquitard between the Kuwait group and Dammam aquifer. The initial salinity for the Kuwait group and Dammam aquifer/Rus formation is set to 9 and $6 \mathrm{~kg} / \mathrm{m}^{3}$, respectively. Again, a linear gradient in initial concentration is defined within the aquitard.

No-flow boundary conditions for both the fluid flow and solute transport equations are implemented at the top and bottom extents of the saturated portion of the model, as well as along the symmetry axis $(r=0 \mathrm{~m})$ for depths where the ASR well is not screened. Fixed pressure and salinity equal to the initial conditions are implemented on the boundary at the right-hand side of the model, which is placed several kilometers away so that it does not influence flow in the region of interest near the well.
Along the screened portion of the well, an inward flux boundary condition is specified such that:

$$
\boldsymbol{n} \cdot \boldsymbol{q}=\frac{\text { injRate }}{2 \pi r_{0} b} \operatorname{pump}(t)
$$

where $\boldsymbol{n}$ is the normal vector, injRate is the volumetric rate of fluid injection or withdrawal $\left(\mathrm{m}^{3} / \mathrm{s}\right), r_{0}$ is the well radius ( $\mathrm{m}), b$ is the screened length of the well $(\mathrm{m})$, and $\operatorname{pump}(t)$ is defined as:

$$
\operatorname{pump}(t)=\left\{\begin{aligned}
1 & \text { injection phase } \\
-1 & \text { recovery phase } \\
0 & \text { storage phase }
\end{aligned}\right.
$$

For the solute transport equation, boundary conditions at the screened portion of the well are:

$$
\boldsymbol{n}(-\phi \boldsymbol{D} \nabla C+\boldsymbol{q} C)= \begin{cases}\boldsymbol{n} \cdot \boldsymbol{q} C_{\mathrm{inj}} & \operatorname{pump}(t)>0 \\ \boldsymbol{n} \cdot \boldsymbol{q} C & \operatorname{pump}(t) \leq 0\end{cases}
$$

where $C_{\mathrm{inj}}$ is the salinity of water injected into the well $\left(\mathrm{kg} / \mathrm{m}^{3}\right)$. These boundary conditions for the ASR well allow us to simulate various injection, storage, and recovery schedules.

\section{Flow Modeling Results}

Numerical flow simulations are computed using the baseline aquifer properties outlined in Table 1 , as well as several variations to this model that are given in Table 2. These are not meant to provide a comprehensive investigation of the influence of various aquifer properties but are rather intended to give a general sense of the general flow characteristics. The rates of fluid injection and withdrawal, salinity of the injected water, and injection and recovery schedule are the same for all these scenarios, with values representative of typical proposed operations taken from Mukhopadhyay and Al-Otaibi (2002). We use injRate $=1310 \mathrm{~m}^{3} / \mathrm{d}$ for both injection and recovery phases, and $C_{\mathrm{inj}}=0.5 \mathrm{~kg} / \mathrm{m}^{3}$ for the salinity of injected water. Injection takes place for the first 5 years, followed by 10 years of storage where no pumping occurs, then 1 year of withdrawal, and finally 4 years of no pumping for a total simulation time of 20 years.

The screened portion of the ASR well for the baseline model, which corresponds to run 000 in Table 2, is $50-\mathrm{m}$ long and is centered at the middle of the Dammam aquifer at a depth of $160 \mathrm{~m}$. The screened length of the well is varied in runs 000 to 002 ; run 002, with the well screen occupying the entire Dammam formation, corresponds to the "reference run" in Mukhopadhyay and Al-Otaibi (2002). Figure 4A shows several snapshots of the subsurface salinity at different simulation times for the baseline model (run 000). It is clear that most of the flow is restricted to the Dammam aquifer, although there is some leakage into the aquitard near the well. Fresh water that enters the aquitard is not easily recovered during the recovery phase, leaving behind a thin lens of injected water that can be seen on the 16-year snapshot of Figure 4A. 
Table 2

Variations in Aquifer Parameters for Different Numerical Simulations

\begin{tabular}{|c|c|c|c|c|c|c|}
\hline \multirow[b]{2}{*}{ Run Number } & \multirow{2}{*}{$\begin{array}{l}\text { Screened Length } \\
\text { of Well, } b(\mathbf{m})\end{array}$} & \multicolumn{2}{|c|}{$\begin{array}{c}\text { Correlation Lengths for } \\
\text { Dammam Permeability (m) }\end{array}$} & \multirow{2}{*}{$\begin{array}{l}\text { Multiplier for Aquitard } \\
\text { Vertical Permeability }\end{array}$} & \multicolumn{2}{|c|}{$\begin{array}{l}\text { Multiplier for Dammam } \\
\text { Dispersivity }\end{array}$} \\
\hline & & Horizontal & Vertical & & Longitudinal, $\alpha_{L}$ & Transverse, $\alpha_{T}$ \\
\hline 000 & 50 & & • & $\bullet$ & $\bullet$ & \\
\hline 001 & 25 & & - & - & $\bullet$ & \\
\hline 002 & 80 & & • & $\bullet$ & $\bullet$ & \\
\hline 003 & 50 & 500 & 80 & • & $\bullet$ & \\
\hline 004 & 50 & 80 & 80 & - & $\bullet$ & \\
\hline 005 & 50 & 500 & 10 & $\bullet$ & $\bullet$ & \\
\hline 006 & 50 & & • & 0.1 & $\bullet$ & \\
\hline 007 & 50 & & $\bullet$ & $\bullet$ & 0.1 & 0.1 \\
\hline 008 & 50 & 500 & 80 & 0.1 & 0.1 & 0.1 \\
\hline 009 & 50 & 500 & 10 & 0.1 & 0.1 & 0.1 \\
\hline 010 & 50 & 80 & 80 & 0.1 & 0.1 & 0.1 \\
\hline
\end{tabular}
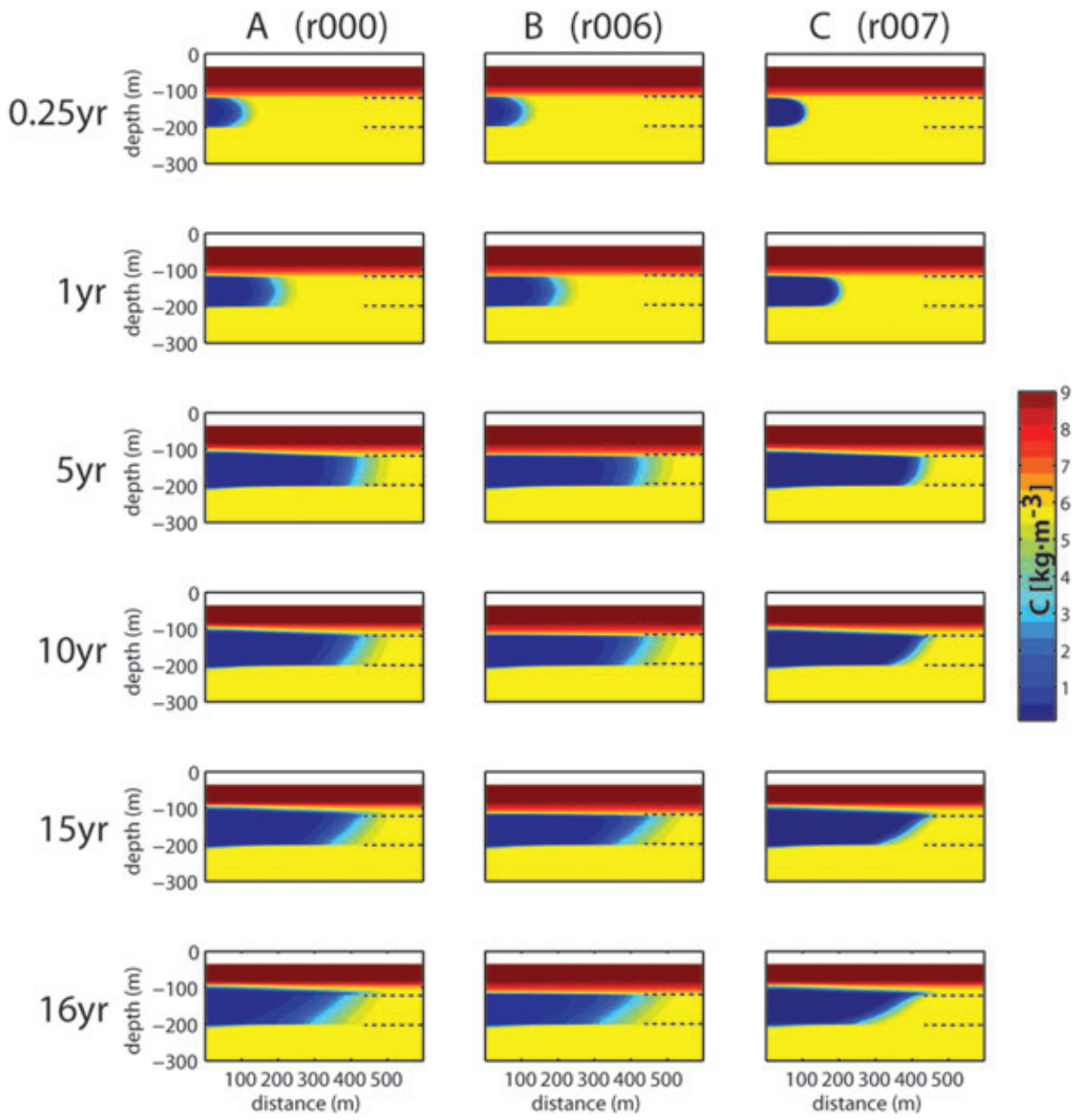

Figure 4. Flow simulation snapshots of aquifer salinity for (A) the baseline model parameters (r000) and two variations on the baseline model: (B) aquitard vertical permeability reduced by an order of magnitude (r006) and (C) dispersivity within the Dammam aquifer reduced by an order of magnitude (r007). For all three cases, injection occurs during years 1 to 5 , followed by a storage phase from years 6 to 14, withdrawal during year 15, followed again by storage until the end of the simulation at year 20. Black-dashed lines outline the depth range of the Dammam aquifer. 
In Figure 4B, flow modeling results are shown for the case where the baseline model is modified by reducing the aquitard vertical permeability by an order of magnitude (run 006). This limits the amount of fluid that leaks into the aquitard but does not significantly alter the general flow characteristics. Figure 4C illustrates the effect of reducing the baseline model longitudinal and transverse dispersivity within the Dammam aquifer by an order of magnitude (run 007). This results in a sharper concentration gradient at the plume front, as well as a steeper tilt of the fresh water/saline water interface.

Buoyancy effects become dominant after year 5 when the injection has stopped and is evident as the characteristic tilting (Ward et al. 2007) of the fresh water front that can be seen on the 10- and 15-year images. Fluid withdrawal during year 16 produces several effects that can be seen in the bottom panels of Figure 4: (1) an increase in the width of the diffuse zone between the natural aquifer and the injected fresh water and (2) less regression of the fresh water front for the fluid "trapped" in the aquitard compared with fluid in the aquifer due to the contrast in hydraulic permeability between these units. This latter effect is diminished in Figure 4B because the reduced aquitard vertical permeability decreases the amount of fresh water that enters the aquitard during the injection and storage phases.

Figure 5 illustrates the general motion of the injected fresh water plume during different ASR phases by plotting the center of mass computed from the differential salinity at various simulation times for the baseline model, that is:

$$
\left[\begin{array}{l}
r_{\mathrm{cm}} \\
z_{\mathrm{cm}}
\end{array}\right]=\frac{\sum_{i}\left[C_{i}(t)-C_{i}(t=0)\right]\left[\begin{array}{l}
r_{i} \\
z_{i}
\end{array}\right]}{\sum_{i}\left[C_{i}(t)-C_{i}(t=0)\right]}
$$

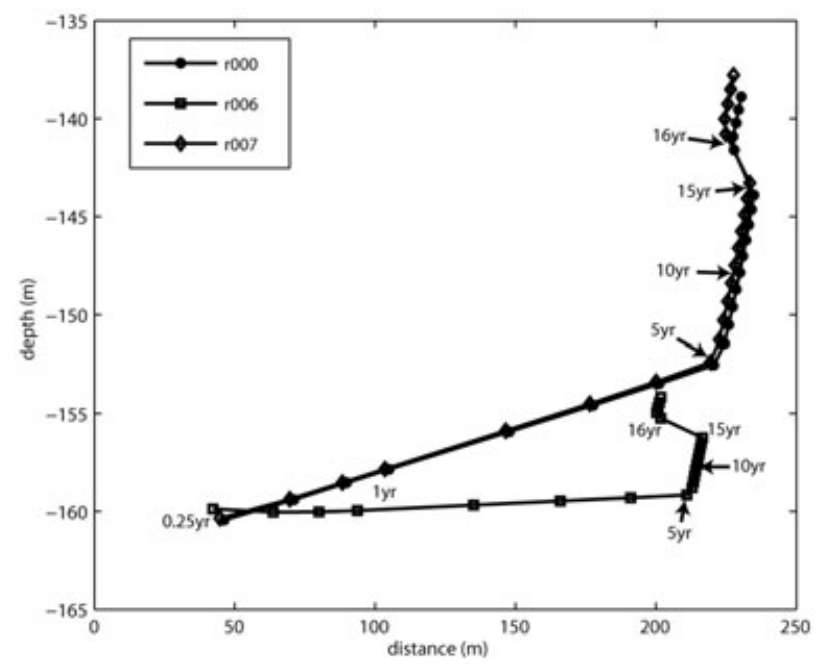

Figure 5. Movement of the center of mass of the injected fresh water throughout the ASR simulation for simulations r000, r006, and r007 shown in Figure 4. The effect of the reduced aquitard vertical permeability (r006) is clearly evident.
Note that this calculation is applied to a single vertical plane through the axisymmetric model; the true center of mass always remains along the well axis. Additionally, Equation 8 assumes that a constant discretization is used in the $r$ - and $z$-directions. The background salinity before pumping occurs, $C(t=0)$, is subtracted from the salinity at each time step to isolate changes due to pumping.

Motion of the plume is mostly lateral during the injection phase that takes place over the first 5 years, followed by primarily vertical motion during the storage phase from years 5 to 15 , then lateral retreat with some vertical rise during the recovery phase between years 15 and 16 , and finally a return to the general storage phase trend. The reduced aquitard vertical permeability in r006 has a clear impact on the vertical motion of the plume compared with the other two scenarios. In the case of reduced aquifer dispersivity ( $\mathrm{r} 007$ ), a slight increase in vertical motion of the plume is observed in comparison with the baseline model.

Runs 003 to 005 investigate the influence of hydraulic permeability heterogeneity within the Dammam aquifer using models with different vertical and horizontal correlation lengths (Table 2) shown in Figure 6. Each permeability model is generated through sequential Gaussian simulation using the same lognormal permeability target histogram. The lognormal distribution has mean -12 and standard deviation 0.35 , which is representative of the
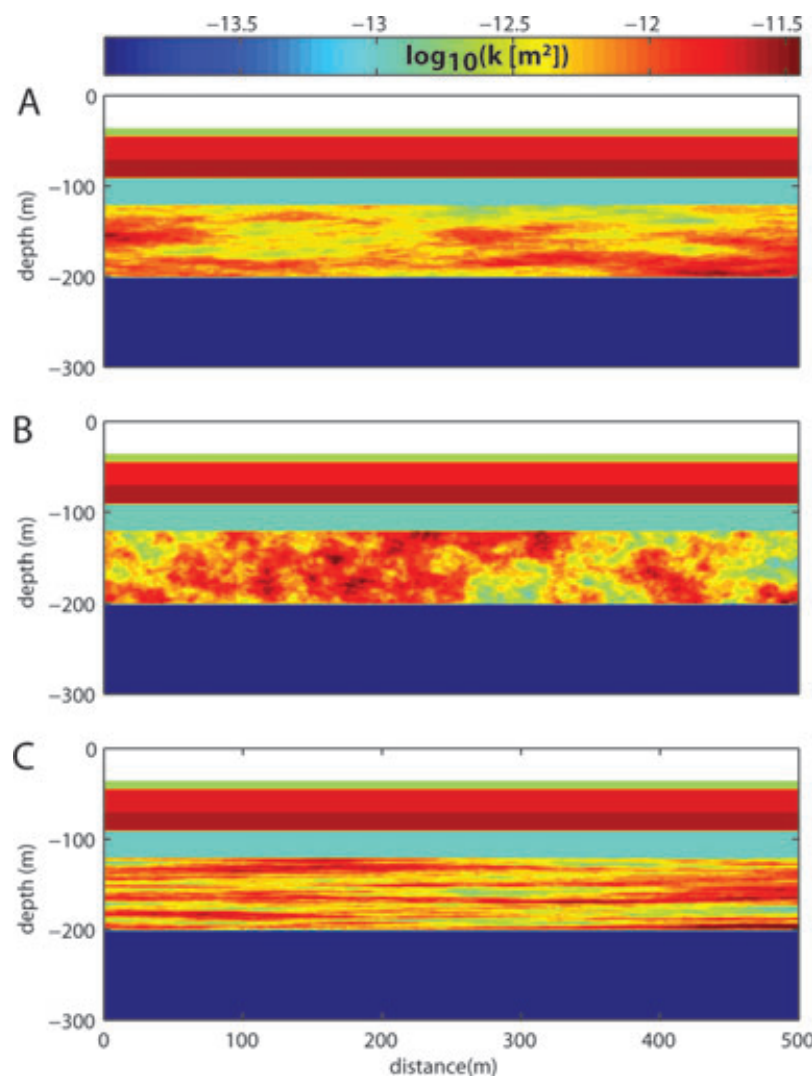

Figure 6. Hydraulic permeability models with different correlation lengths used for numerical simulations. (A) $500 x$ $80 \mathrm{~m}$ used in runs 003 and 008 , (B) $80 \times 80 \mathrm{~m}$ used in runs 004 and 010, (C) $500 \times 10 \mathrm{~m}$ used in runs 005 and 009 . 
permeability range in the Dammam aquifer reported by Mukhopadhyay and Al-Otaibi (2002, Table 1). This standard deviation may underrepresent the variation of permeability of the karst aquifer and is a focus of future work. Heterogeneous porosities are defined within the model based on a nonlinear mapping to the permeability value at each location. Finally, runs 008 to 010 involve combinations of aquifer heterogeneity with the altered aquitard permeability and aquifer dispersivity investigated in runs 006 and 007.

The use of a two-dimensional (2D) hydraulic permeability field within an axisymmetric model is equivalent to concentric tubes of constant permeability around the central well, which results in radially weighted hydraulic conductance values (e.g., Langevin 2008). This model properly accounts for the volumetric distribution of injected or recovered water but presumes that there is no flow in the angular direction (perpendicular to the $r-z$ plane) and is not representative of realistic flow patterns due to 3D heterogeneity.

Salinity snapshots from the flow simulations for these heterogeneous cases are illustrated in Figure 7. Two simulations are run for each of the three different heterogeneity correlation lengths shown in Figure 6. In columns
A (r003), C (r004), and E (r005), the only alteration to the baseline model is the introduction of aquifer heterogeneity. In columns B (r008), D (r010), and F (r009), the reduced aquitard vertical hydraulic permeability and Dammam aquifer dispersivity outlined in Table 2 are also included in the modeling. Differences in hydraulic permeability control the general flow patterns for the three cases of heterogeneity. As with runs 006 and 007, the decreased aquifer dispersivity results in a sharper front of the injected fresh water plume and the decreased aquitard vertical permeability results in decreased leakage of fresh water into the aquitard (Figure 7 columns B, D, and F). The fresh water plume does not extend as far into the aquifer for the heterogeneous cases (Figure 7) compared with the homogeneous ones (Figure 4) due to the fact that the heterogeneous porosity models have a slightly higher average porosity than the homogeneous value.

\section{Geophysical Response to ASR}

Time-varying geophysical signatures are computed for the various flow scenarios from the dynamic changes in water properties due to variations in pressure and salinity (at a constant temperature of $15^{\circ} \mathrm{C}$ ), combined with

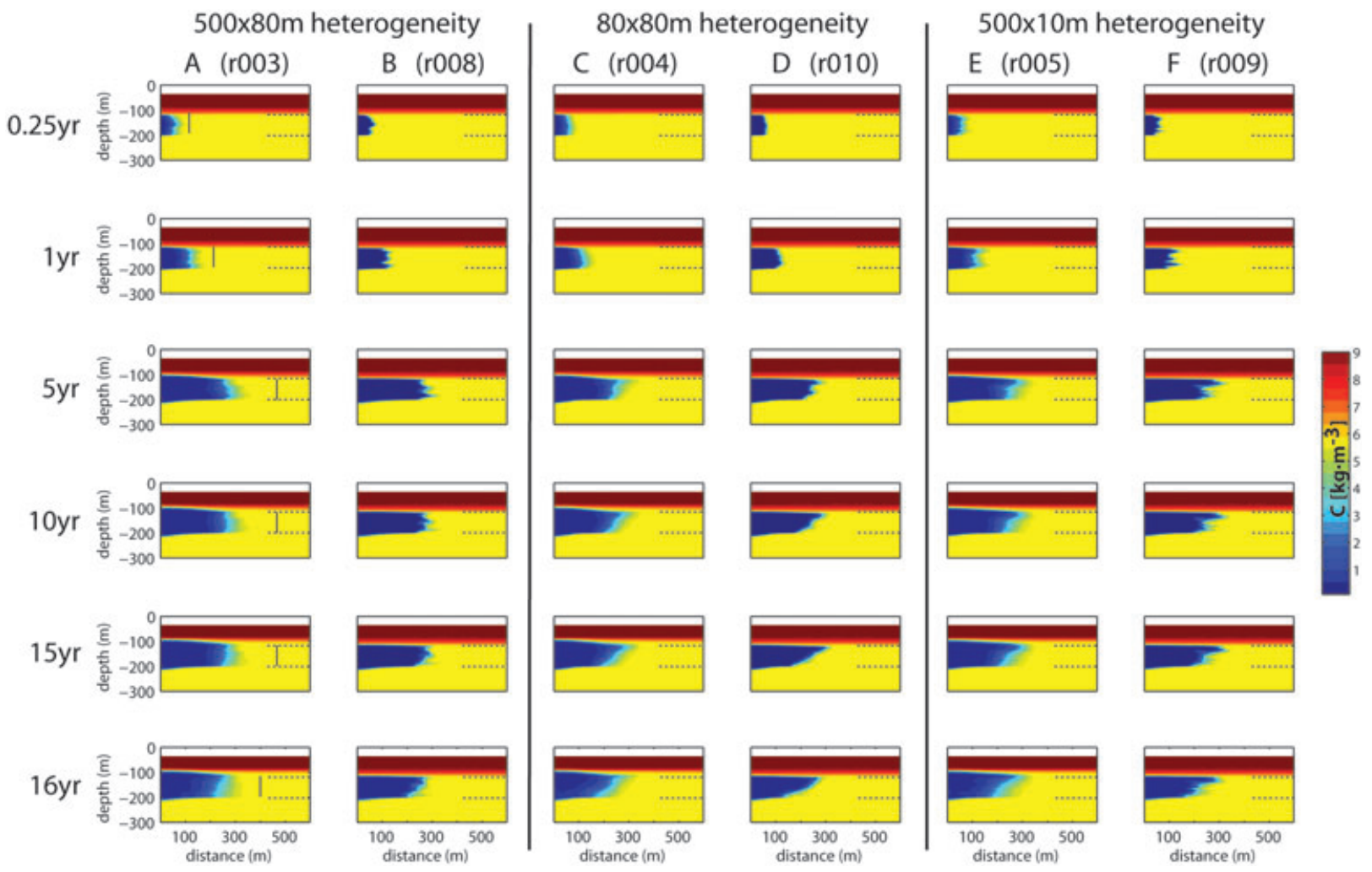

Figure 7. Flow simulation snapshots of aquifer salinity for runs that include heterogeneity within the Dammam aquifer. Two simulations are run for each of the three different heterogeneity correlation lengths illustrated in Figure 6 . In columns A (r003), C (r004), and $\mathrm{E}$ (r005), the only alteration to the baseline model is the introduction of aquifer heterogeneity. In columns B (r008), D (r010), and F (r009), the reduced aquitard vertical hydraulic permeability and Dammam aquifer dispersivities outlined in Table 2 are also included in the modeling. For all six cases, injection occurs during years 1 to 5, followed by a storage phase from years 6 to 14, withdrawal during year 15, followed again by storage until the end of the simulation at year 20. Black-dashed lines outline the depth range of the Dammam aquifer, whereas the vertical lines in column $B$ show the rough extent of the injected water for the lower porosity baseline model (r000). 
static matrix properties such as porosity, permeability, and density. Water properties computed as a function of temperature, pressure, and salinity using relationships provided by Batzle and Wang (1992) and Keller and Frischknecht (1966) include density, electrical resistivity, bulk modulus, viscosity, and $\mathrm{P}$-wave velocity. The first three of these properties are displayed in Figures 8A, 8C, and $8 \mathrm{E}$ as a function of salinity within the range of interest for this study. The following sections discuss in more detail how these properties are used to compute bulk properties used to compute the geophysical response using DC resistivity, TEM, and seismic survey methods.

One method that is not discussed in detail is gravity, which does have potential utility in ASR projects (Davis et al. 2008), but is likely limited to scenarios that involve relatively shallow unconfined aquifers where injected water displaces air, resulting in a approximately $1000 \mathrm{~kg} / \mathrm{m}^{3}$ density contrast within the pore space. In this study, the injected fresh water displaces saline water, resulting in a maximum fluid density change of approximately $6 \mathrm{~kg} / \mathrm{m}^{3}$. Figure $8 \mathrm{~B}$ shows the bulk density computed for three different porosities, assuming a fixed matrix density of $2870 \mathrm{~kg} / \mathrm{m}^{3}$ (dolomite) and the range of fluid densities illustrated in Figure 8A. The change in bulk density as a function of fluid salinity is very small; the maximum change is approximately $1 \mathrm{~kg} / \mathrm{m}^{3}$ for the $20 \%$ porosity case. Approximating the injected fresh water as a spherical anomaly with $1 \mathrm{~kg} / \mathrm{m}^{3}$ density contrast, $100-\mathrm{m}$ radius, and centered at a depth of $160 \mathrm{~m}$ yields a maximum gravity anomaly of approximately $1 \mu \mathrm{Gal}$ on the Earth's surface, which is beyond the limit of modern gravimeters.

The self-potential method, also not discussed in further detail, is likely limited to more shallow ASR scenarios. Two relevant source components of the self-potential signal include (1) injection-induced flow and (2) concentration gradients at the fresh water/saline water interface (e.g., Darnet et al. 2004). Both of these, however, would likely result in very small measurable potentials on the earth surface due to the depth of the Dammam aquifer in this study. In shallower settings, the latter component of the self-potential signal may provide useful information about the extent of the injected plume, whereas the former is most sensitive to flow close to the injection or recovery wells.

The following sections provide a sensitivity analysis for the different geophysical methods with respect to the ASR experiment. That is, the results are presented as the forward geophysical response to the various flowinduced models. For this synthetic case study, we have purposefully avoided presenting inversion results of the simulated forward data. The focus of this paper is not on specific inversion strategies and their ability to resolve model parameter changes in the face of measurement and model errors; rather, it is meant to highlight the sensitivity of different geophysical methods to the flow-induced model changes.

These forward modeling results have an implicit connection to the inverse problem in that significant changes
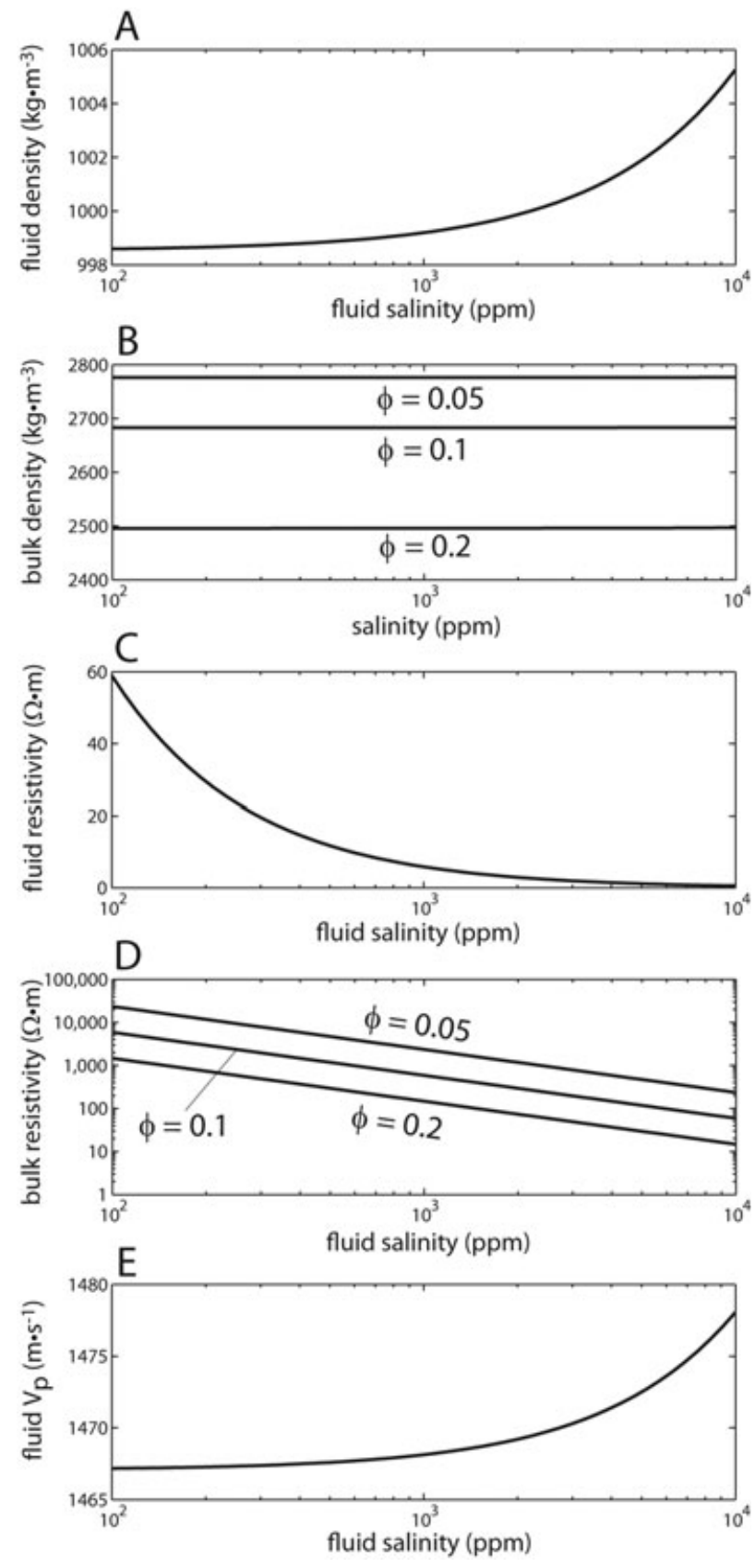

Figure 8. Effect of fluid salinity within the range of interest for this study on fluid density (A), bulk density computed for different porosities and matrix density $2870 \mathrm{~kg} / \mathrm{m}$ (B), fluid resistivity (C), bulk resistivity computed using Archie's law for three different porosities (D), and fluid P-wave velocity $(\mathrm{E})$.

in simulated data for two different models contain the information (sensitivity) needed to provide information about the model changes. Likewise, simulated data for two different models that show little-to-no difference in response will be unable to image the underlying model changes, regardless of the specific inversion used.

\section{Resistivity}

Changes in subsurface bulk electrical resistivity can be attributed to the injection of fresh water into the 
more saline Dammam aquifer. Archie's law (Archie 1942) is a commonly used relationship that relates the bulk resistivity to fluid resistivity, porosity, and water saturation:

$$
\rho_{\mathrm{b}}=a \rho_{\mathrm{f}} \phi^{-m} S_{\mathrm{w}}^{-n}
$$

Here, $\rho_{\mathrm{b}}$ is the bulk resistivity $(\Omega \cdot \mathrm{m}), \rho_{\mathrm{f}}$ is the fluid resistivity $(\Omega \cdot \mathrm{m}), \varphi$ is the porosity, and $S_{\mathrm{w}}$ is the fractional water saturation. The coefficients $a, m$, and $n$ vary with rock type, but typical values are $a \sim 1, m \sim 2$, and $n \sim 2$. Fluid resistivity is defined as a function of the salinity:

$$
1 / \rho_{\mathrm{f}}=F \sum_{i} u_{i}\left|z_{i}\right| C_{i}
$$
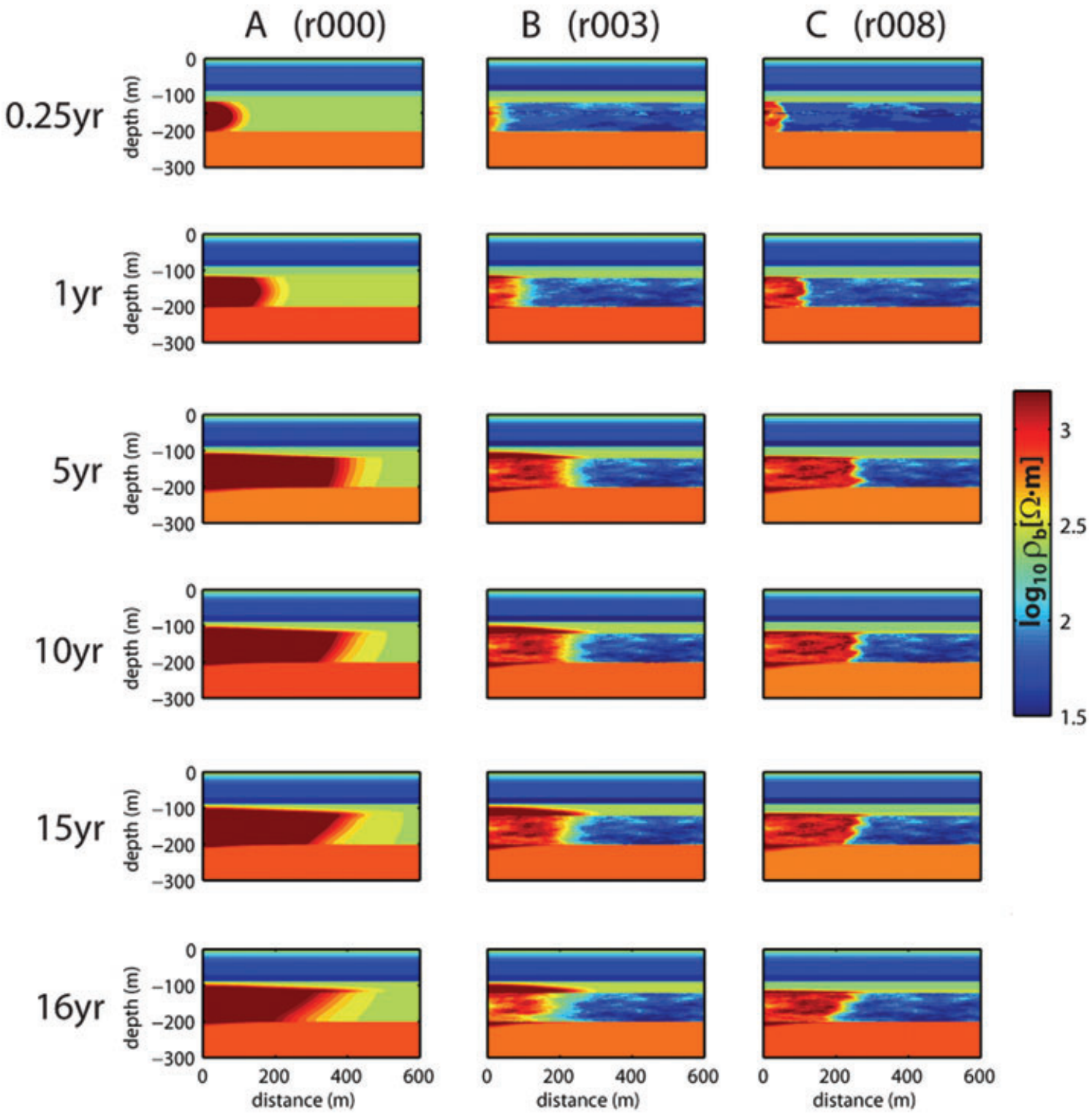

Figure 9. Snapshots of bulk electrical resistivity computed from the flow simulations for (A) the baseline model parameters (r000) and two variations on the baseline model: (B) heterogeneity within the Dammam aquifer with correlation length $500 \times$ $80 \mathrm{~m}(\mathrm{r003})$ and $(\mathrm{C})$ reduced aquitard vertical permeability and aquifer dispersivity in addition to the aquifer heterogeneity (r008). 
For example, the higher aquitard vertical permeability in Figure 9B compared with Figure 9C results in relatively more flow in to the low-porosity aquitard. The combination of reduced salinity and porosity results in further increases in electrical resistivity within the aquitard. These three cases are used to illustrate changes in the predicted DC resistivity response with time, as well as differences due to the different modeling cases at a given simulation time.

The DC resistivity response is simulated using a 3D model that is generated by revolving the bulk resistivity images in Figure 9 about a vertical axis through the origin. The modeled data consist of a single $2 \mathrm{D}$ profile across the center of the model using an inverse Wenner-Schlumberger array with 50 electrodes, each separated by $40 \mathrm{~m}$ (a-spacing). Simulated data are computed using a code that is based on the transmission network approach discussed by Zhang et al. (1995) and Shi (1998). Changes in the modeled response are presented as differential apparent resistivity pseudosections, where the apparent resistivity is given by the product of the geometric factor, $K=\pi a(n+1) n(\mathrm{~m})$, with the ratio of the measured potential difference to the injected current, $\Delta V / I(\Omega)$.

$$
\rho_{\mathrm{a}}=K \frac{\Delta V}{I}
$$

Differential apparent resistivities are simply the point-bypoint percent differences between any two pseudosections.
Time-lapse changes in apparent resistivity for case r000 are illustrated in Figures 10A and 10B. Figure 10A displays the total percent change in apparent resistivity for each simulation time with respect to the preinjection state, whereas Figure 10B illustrates the incremental change in apparent resistivity between neighboring simulation times. This comparison is repeated for r003 (Figures 10C and 10D) and r008 (Figures 10E and 10F). In all the cases, outward progression of the fresh water plume is evident as increased apparent resistivity during the injection phase. This is followed by a more subtle increase in resistivity associated with the upward and outward movement of the fresh water under its buoyancy during the storage phase. Slight decreases in apparent resistivity are observed after the recovery phase, as seen in the bottom pseudosections in Figures 10B, 10D, and 10F.

Figure 11 shows the differences in modeled apparent resistivity (\%) for the different flow scenarios in Figure 9. The differences between the baseline model ( $\mathrm{r} 000)$ and the case with $500 \times 80-\mathrm{m}$ aquifer heterogeneity and elevated aquitard permeability and aquifer dispersivity (r003) are illustrated in Figure 11A. Much of the large ( 50\%) difference between these cases comes from the difference in background resistivity of the Dammam aquifer for the homogeneous and heterogeneous models, although the influence of the injected fresh water is also evident over the various time steps. Figure $11 \mathrm{~B}$ shows the apparent resistivity changes between the two heterogeneous aquifer cases from Figure 9 (r003 and r008), which only differ in their aquitard permeability and aquifer dispersivity, and
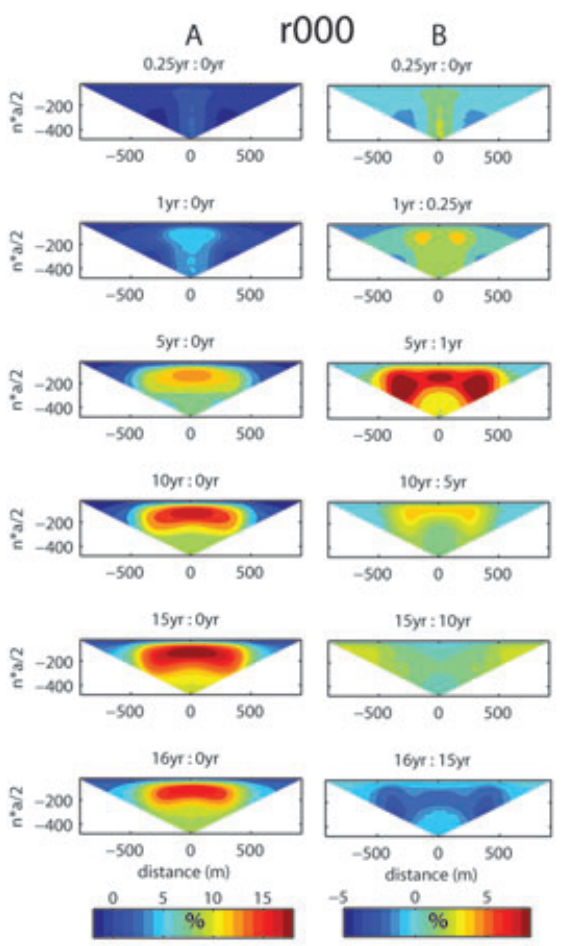
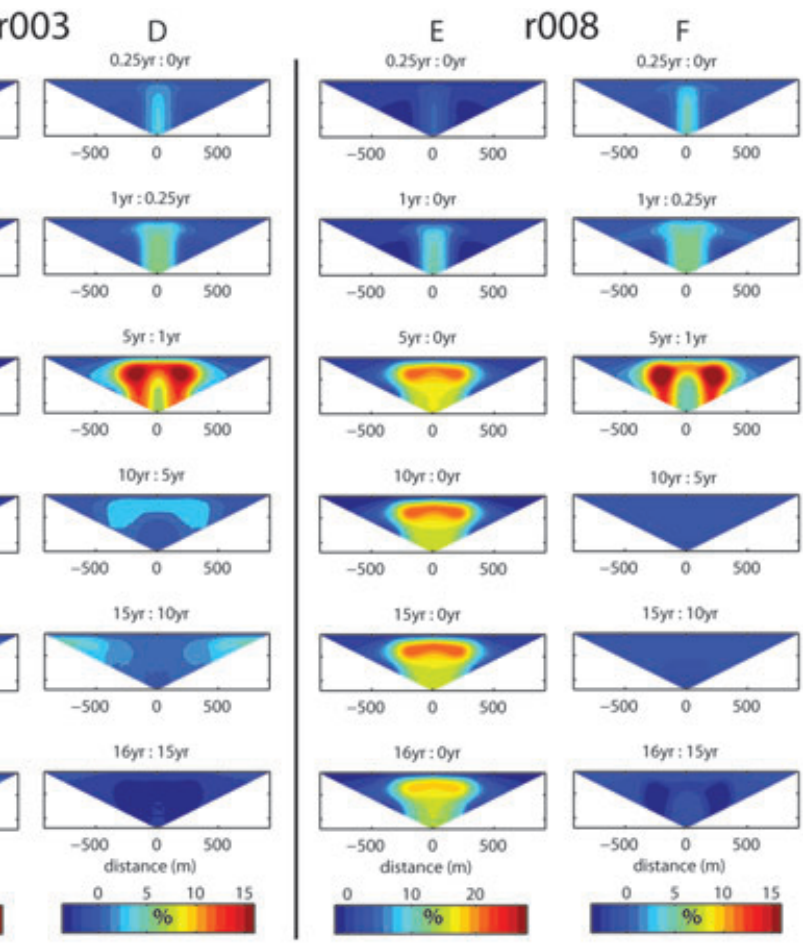

Figure 10. Time-lapse differential apparent resistivity (\%) pseudosections for cases r000 (A and B), r003 (C and D), and r008 $(\mathrm{E}$ and $\mathrm{F})$. For each modeling scenario, the total differences at each time step are shown with respect to the preinjection state $(\mathrm{A}, \mathrm{C}$, and $\mathrm{E})$ as well as incremental changes with respect to the previous simulation time step (B, D, and F). Note that different color scales are used for each column. 


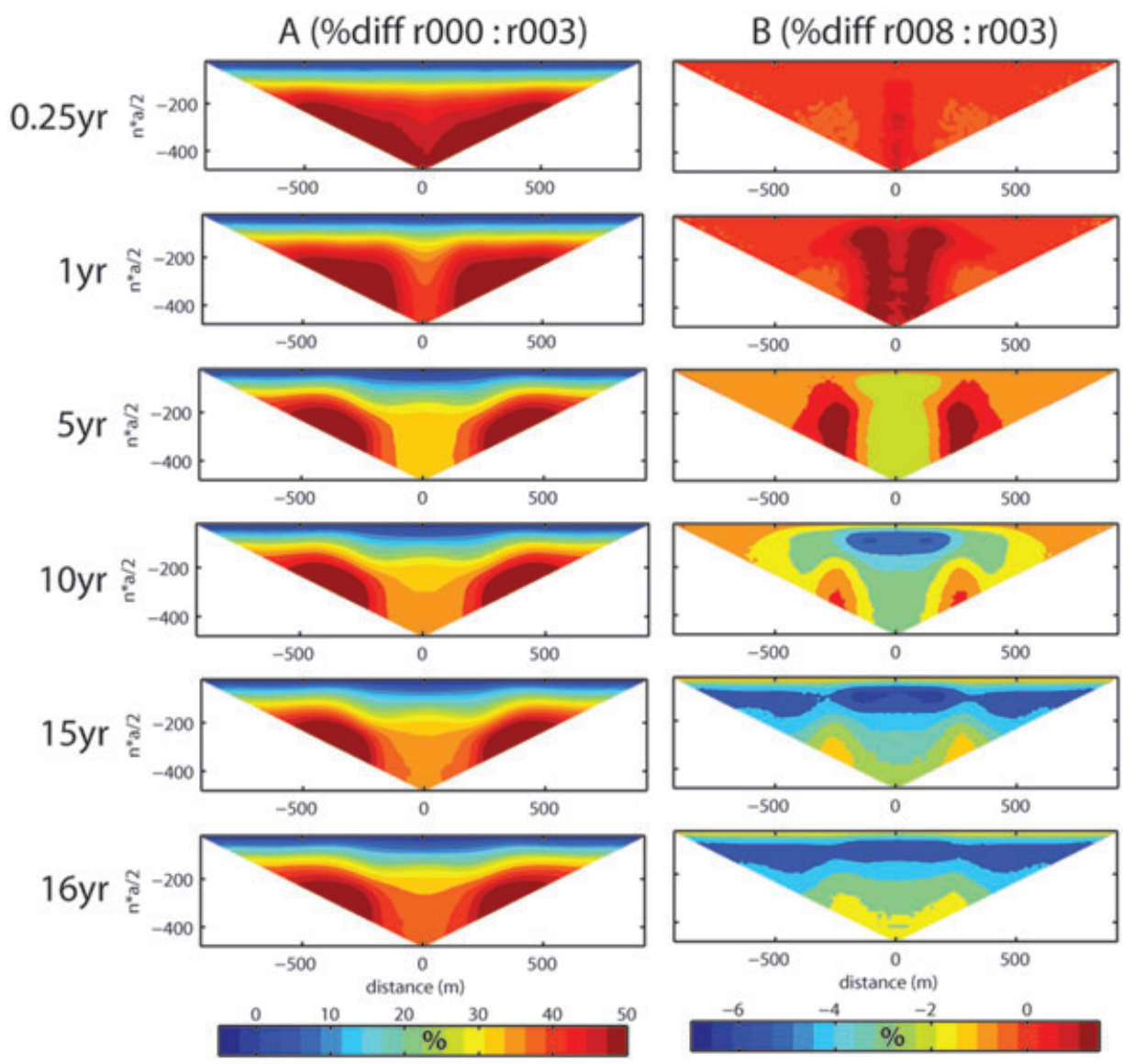

Figure 11. Differential apparent resistivity (\%) pseudosections between the models illustrated in Figure 9 at various simulation times. (A) r000 vs. r003, and (B) r008 vs. r003. Differences highlight the changes in flow patterns between different models. Note that the changes in (A) are much larger than those in (B).

therefore their flow characteristics. During the injection phase, r008 exhibits a slightly higher $(\sim 2 \%)$ apparent resistivity than r003 due to the greater distance that the fresh water has migrated into the aquifer (Figure 9), which is apparent in Figure 11B. From year 5 onward, there is also a decrease in the apparent resistivity of r008 relative to r003 in the center of the pseudosection. This is attributed to the decrease in fresh water moving upward through the aquitard in case r008, which has reduced vertical aquitard permeability.

There are many possible apparent resistivity comparisons to make between the different flow simulations at various time steps. The purpose of the relatively small subset of examples provided here is to give the reader a sense of the magnitudes and characteristics of these changes, which is representative of the various flow simulations in this study. This forward modeling exercise is meant to illustrate the sensitivity of DC resistivity measurements to changes in subsurface flow patterns related to the ASR experiment. One still needs to consider the resolution to which these flow patterns can be resolved in an inversion given these data and their geometry, as well as noise that can be expected to be recorded in the field.

\section{Time-Domain Electromagnetics (TEM)}

TEM soundings provide another means for characterizing the subsurface electrical resistivity structure and have been used previously in numerous hydrogeologic studies (e.g., Auken et al. 2006; Danielsen et al. 2003; Fitterman and Stewart 1986). In contrast with the galvanically coupled DC resistivity method, TEM is an inductive technique, which may provide some practical advantage over DC resistivity in the desert environment where high electrode contact resistances can be an issue (Al-Ruwaih and Ali 1986). The basic principle involves passing a constant current through a loop of wire on the Earth's surface, which produces a primary magnetic field. This current is then rapidly turned off, inducing a ring of horizontal currents in the subsurface that immediately maintain the initial magnetic field. The current system subsequently decays as it diffuses downward through the subsurface resistivity structure, producing a time-varying secondary magnetic field that is recorded by a receiving coil on the surface.

The TEM response is computed from the same bulk resistivity models used for the DC resistivity example in the previous section, although we are currently restricted to the one-dimensional (1D) forward modeling code, EMMA (Auken et al. 2002). Because of the inherently 
3D character of the injected fresh water "bubble," this 1D forward modeling exercise is somewhat limited, particularly for early simulation times when the lateral extent of the injected fresh water is relatively small compared with the aquifer depth. This is due to the nature of the increasing volume of sensitivity as the induced current system diffuses downward through the earth structure (Nabighian and Macnae 1991), sampling both the background resistivity structure and the anomalous volume. By extracting 1D resistivity profiles from the center of the axisymmetric models, we are effectively investigating the maximum observable TEM response, when the extent of the injected fresh water is much larger than the dimension of the transmitting loop.

Although smaller transmitter loops can be used to improve lateral resolution, the signal strength (and therefore depth of investigation) depends on the transmitter moment, proportional to the product of the transmitting loop area and the current in the loop. Therefore, to achieve the same moment as a $100-\mathrm{m}$ rectangular loop with $10 \mathrm{~A}$ of current, a 25-m loop would require $160 \mathrm{~A}$ of current, which is well beyond the capability of commercial TEM systems. For the current study, the TEM response is simulated using a 100-m square transmitting loop with $25 \mathrm{~A}$, and a vertically oriented receiving coil at the center of the transmitter. The output data are presented as $\mathrm{d} B / \mathrm{d} t$ $\left(\mathrm{V} / \mathrm{m}^{2}\right)$ decay curves, which are also converted to apparent resistivities. Error bars on these figures result from the default EMMA noise function that is applied to the data, which has a magnitude of $2.5 \times 10^{-9} \mathrm{~V} / \mathrm{m}^{2}$ at $1 \mathrm{~ms}$ and a slope of -0.5 (i.e., the noise decays as $t^{-0.5}$ ).

Because of the aforementioned limitation of the 1D modeling exercise, we only compare two resistivity models (one preinjection and one postinjection) for modeling scenarios $\mathrm{r} 000$ and $\mathrm{r} 003$. The 1D resistivity models imported into EMMA are extracted at 10-m depth intervals from the center of the bulk resistivity models illustrated in Figure 9. Figure 12 shows the resistivity models for scenarios r000 (Figure 12A) and r003 (Figure 12B), where the top panels correspond to the preinjection state and the bottom panels correspond to the state at the end of injection (year 5). Because of the larger average porosity in the aquifer in r003 compared with $\mathrm{r} 000$, the preinjection resistivity scenarios are quite different. In the r000 case, the aquifer has a higher resistivity than the overlying aquitard, but a lower resistivity than the lower half-space. In the r003 case, however, the aquifer has a lower resistivity than the surrounding layers. In both models, the postinjection aquifer resistivity is significantly higher than the surrounding layers.

Modeling results are displayed in Figure 13A (r000) and Figure 13B (r003), with the decay curves illustrated in the top panels, and apparent resistivities in the bottom panels. For each figure, the preinjection (0 year) result is displayed in black and the postinjection (5 years) result is displayed in gray. It is apparent from these figures that detection of the fresh water injection does not seem feasible for the low-porosity aquifer case (r000), although there is a distinct difference in the preinjection
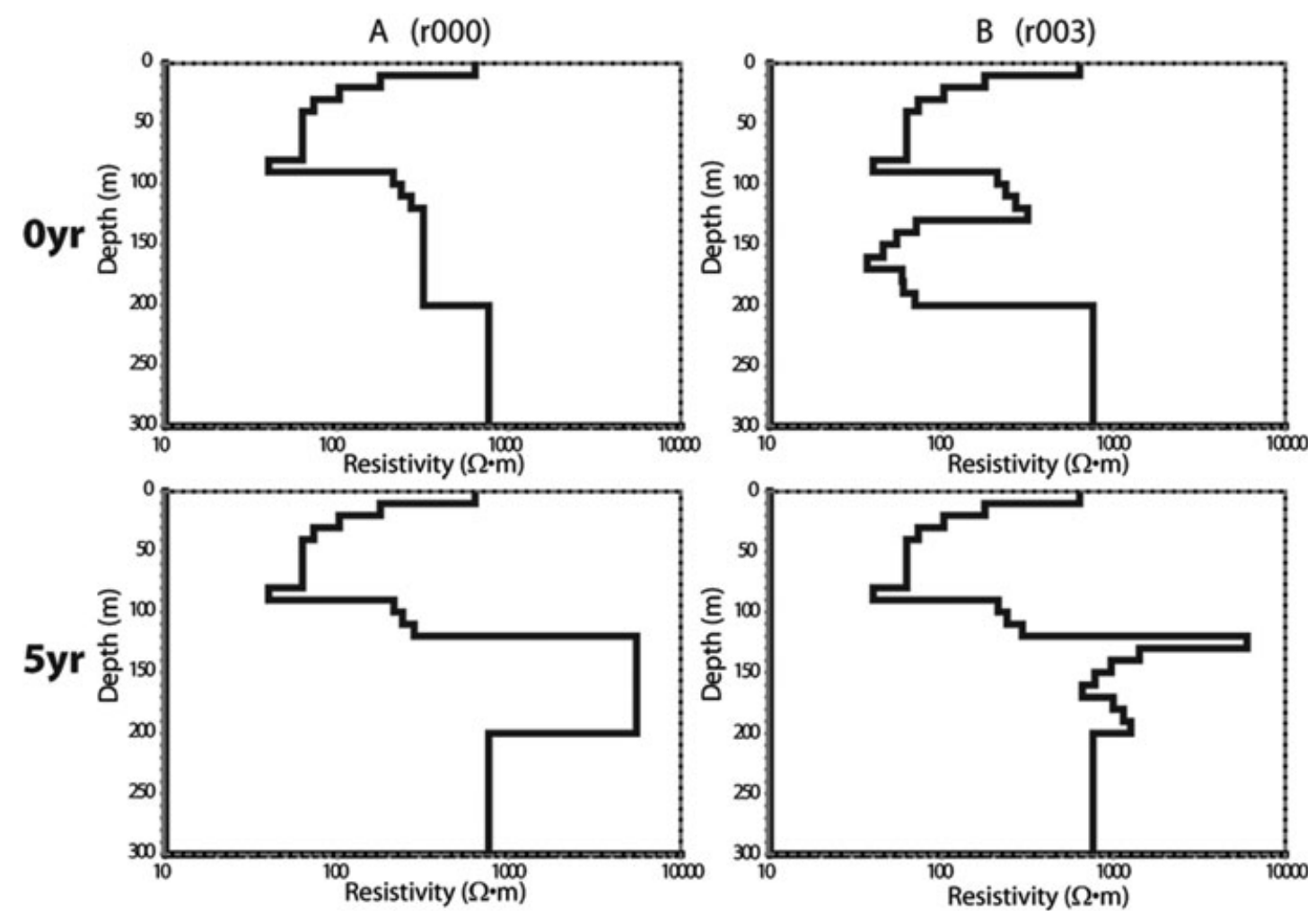

Figure 12. 1D resistivity models used for TEM forward simulations for the baseline model preinjection (A, top) and after 5 years of injection (A, bottom) as well as flow scenario r003 at the same simulation times (B). 

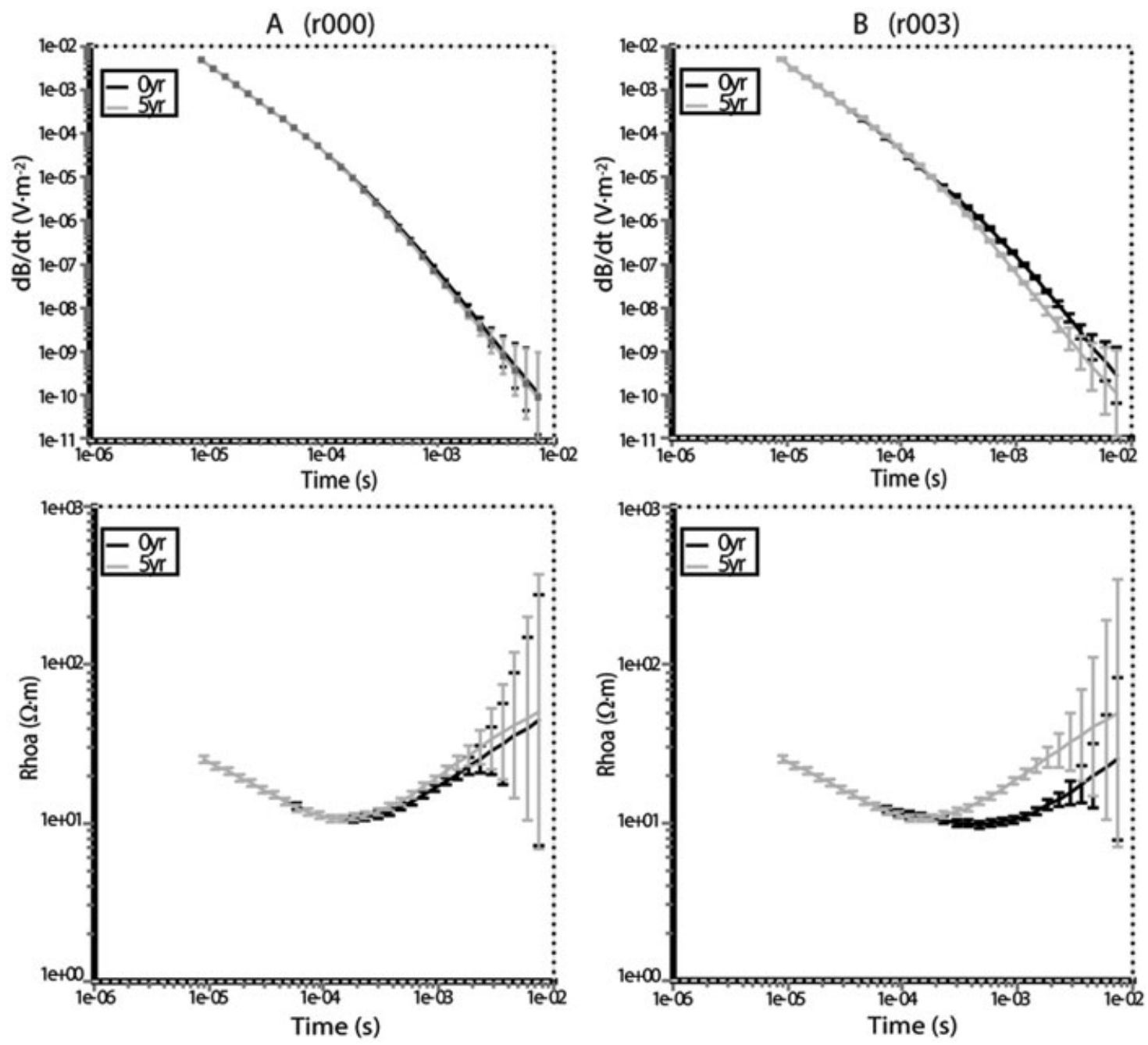

Figure 13. TEM results for the resistivity models shown in Figure 12. Results for the baseline model, r000 (A) are displayed as $\mathrm{d} B / \mathrm{d} t\left(\mathrm{~V} / \mathrm{m}^{2}\right)$ (top) and apparent resistivity $(\Omega \cdot \mathrm{m})$ (bottom). (B) Corresponding results for flow scenario r003. In all figures, the preinjection values are displayed in black, and the postinjection (year 5) results are in gray.

and postinjection TEM responses for the higher porosity aquifer case (r003). This can be attributed to the inherent difficulty in distinguishing resistive targets compared with conductive ones (Fitterman and Stewart 1986). In the r000 case, the intermediate preinjection aquifer resistivity is replaced with a high-resistivity layer, making it difficult to detect. For the r003 case, however, the initial aquifer resistivity is relatively low, making it a good TEM target in contrast with the postinjection resistivity.

\section{A Seismic Monitoring Strategy}

In addition to techniques based on electrical and electromagnetic contrasts, seismic methods offer another possible avenue for monitoring ASR. The primary subsurface processes of relevance are changes in fluid modulus and density due to salinity and temperature changes, and variations in effective stress due to pumping-induced changes in pore pressure. Effective stress variations produce the dominant seismic signature in the context of an ASR experiment, suggesting that seismic methods might be most useful in constraining pore pressure distribution rather than the injected zone of fresh water. This modeling investigation focuses on vertical seismic profiling due to reported technical difficulties in obtaining high-quality surface seismic data on the unconsolidated sands at the study area. For simplicity, we only consider P-wave property variations and acoustic rather than elastic modeling although some additional information might be gained through multicomponent surveys.

For our seismic forward modeling experiment, we consider only scenario r003 and use the same unit designations and porosities described in the flow modeling sequence. Figure 14A depicts a map of $V_{\mathrm{p}}$ over the modeling domain at time zero (preinjection). Velocities in our seismic model vary from $900 \mathrm{~m} / \mathrm{s}$ in the unsaturated near-surface gravel layer to $5210 \mathrm{~m} / \mathrm{s}$ in the basal Dammam/Rus. Intermediate sandstone velocities are estimated from general literature values tabulated in Mavko et al. (1998). Velocities for the shaly aquitard are presumed using Castagna's mudrock relationship (Castagna et al. 1985). Properties for the Dammam itself are calculated using a modified Voigt + critical porosity model 


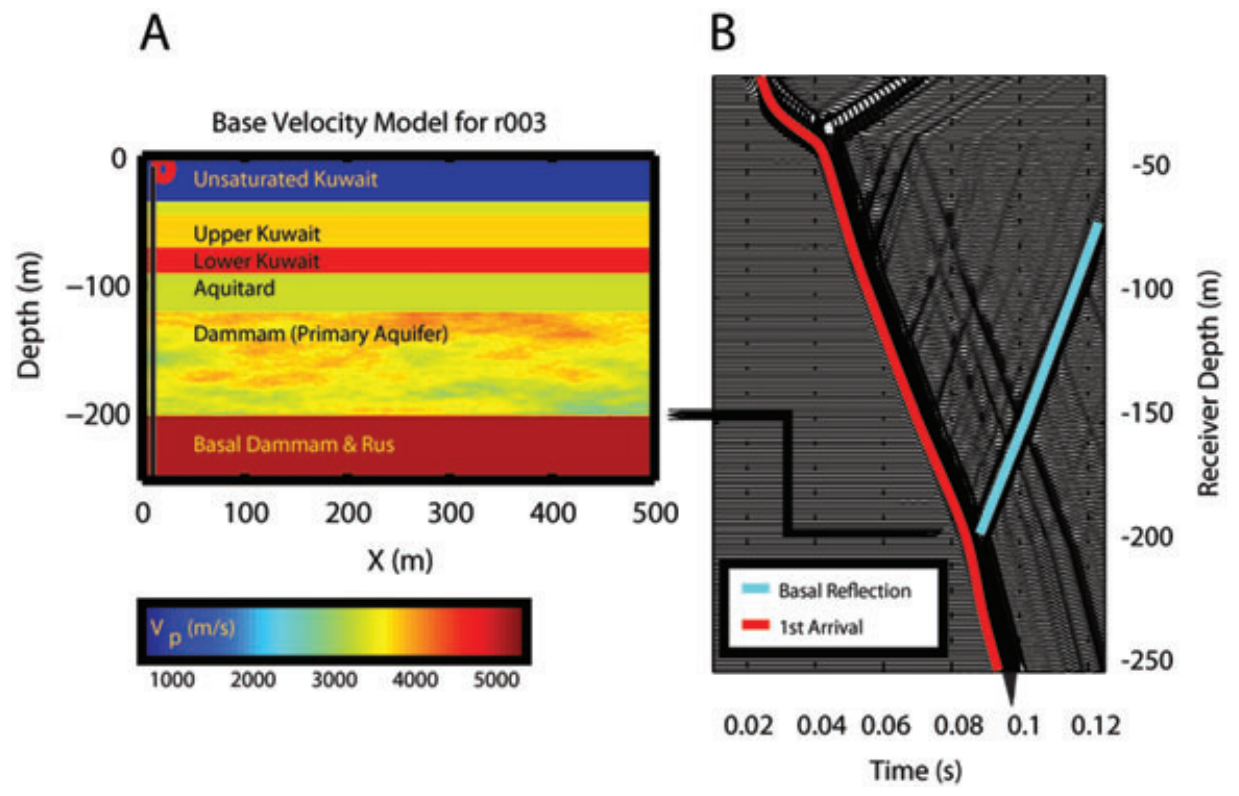

Figure 14. (A) Preinjection velocity model for flow scenario r003, with source location for the near-offset VSP denoted by the red circle and downhole receiver array (blue line). (B) Shot gather for the baseline model generated by a $150 \mathrm{~Hz} \mathrm{Ricker}$ wavelet with the primary transmission arrival is outlined in red, and basal reflection in blue.

calibrated to the Nur/Simmons Bedford limestone dataset (Supporting Information). An important caveat is that none of these values are calibrated to either local field data or measurements from the same geological units at a remote site; the included velocities should only be considered rough estimates included for the purpose of sensitivity calculations until more reliable data become available. To convert the r003 sequence of flow results into seismic properties, all units except for the Dammam are assumed to remain unchanged. Within the Dammam, the frame model and Gassmann fluid substitution discussed in the online Supporting Information are used to estimate property changes due to variations in fluid characteristics (modulus and density) as well as pore pressure.

In modeling the site's seismic response, we consider a near-offset vertical seismic profile, one of the most common type of downhole seismic surveys acquired during monitoring activities. Because spatial sensitivity to localized variations in properties is relevant, we use 2D full wavefield acoustic finite-difference (FD) modeling to estimate the response to pumping activities. The code developed for this task is an explicit time-domain FD solver (eighth order in space, second order in time) similar to the classical scheme described in Dablain (1986) with the sponge absorbing boundary condition developed by Cerjan et al. (1985).

Figure 14A depicts the source position used for the near-offset modeling simulation (red circle) in addition to the receiver array, assumed to be in a well close to the origin of the radial flow model. The offset between the source and the receiver well is $7 \mathrm{~m}$ laterally and the 200 receivers have a vertical spacing of $1.43 \mathrm{~m}$. Figure 14B shows a corresponding shot gather for the baseline model generated by a $150 \mathrm{~Hz}$ Ricker wavelet with the primary transmission arrival outlined in red. As expected, the most visible velocity changes in the background model, visible as variations in the slope of the primary arrival, are the transition between the shallow unsaturated gravel unit and the upper Kuwait group and the transition between the Damman and the Basal Dammam/Rus. Several strong reflections are also visible with the most dominant corresponding to the preceding transitions. The basal Dammam/Rus reflection, outlined in blue, is probably the most useful reflection event for monitoring lateral variations in aquifer properties as it samples velocity changes across the aquifer.

Figure 15A shows the result of using the selected rock physics model to compute the expected changes in P-wave velocity induced by 1 year of aquifer injection in scenario r003, the point of maximum departure from the initial state. A crucial observation is that the zone that experiences significant increases in pore pressure and corresponding decreases in $V_{\mathrm{p}}$ is highly localized within the vicinity of the injection well. Although peak velocity changes near the well are $-55 \mathrm{~m} / \mathrm{s}$, at a $100-\mathrm{m}$ offset velocity departures are on the order of $-10 \mathrm{~m} / \mathrm{s}$, a change of only approximately $0.3 \%$ from baseline levels. Although aquifer heterogeneity does induce vertical and lateral variations in the $\mathrm{P}$-wave properties, the timelapse signature is largely dominated by the distance from the injector. Figure 15B depicts modeled traces with automatic gain control (AGC) applied for three receiver depths; one above $(80 \mathrm{~m})$, one within $(166 \mathrm{~m})$, and one below the aquifer unit $(244 \mathrm{~m})$ with baseline shown in red and recordings after 1 year in blue. As can clearly be seen, the phase and amplitude of the modeled signal change only a small amount in both the direct and reflected components of the waveform, motivating a 


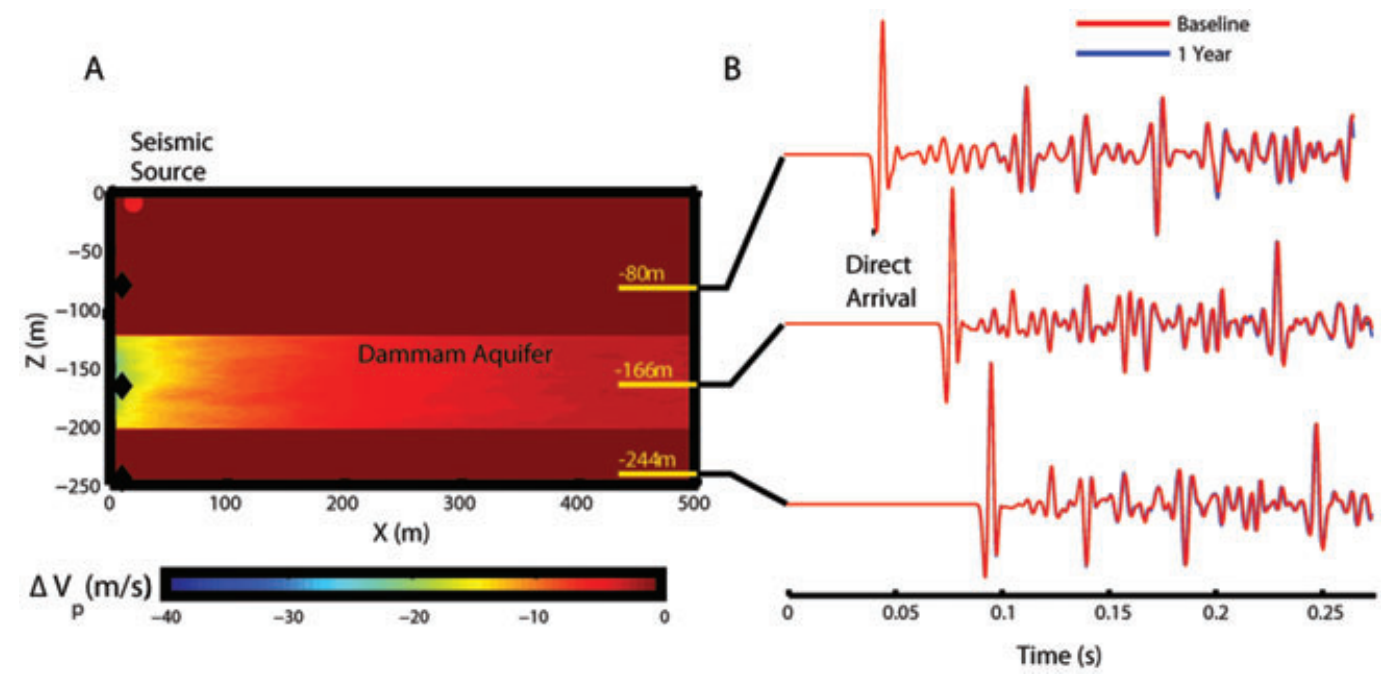

Figure 15. (A) Result of using the selected rock physics model to compute the expected changes in P-wave velocity induced by 1 year of aquifer injection in scenario r003. (B) Modeled traces with AGC applied for three receiver depths; one above $(80 \mathrm{~m})$, one within $(166 \mathrm{~m})$, and one below the aquifer unit $(244 \mathrm{~m})$ with baseline shown in red and recordings after 1 year in blue. Note the difference between baseline and postinjection arrivals is small and difficult to distinguish at this scale.

closer examination to quantitatively determine maximum departure in travel times.

To further explore the expected travel-time variations, both the direct and basal reflection events are handpicked at all receiver levels for both the baseline nearoffset gather and the modeled gather after 1 year of injection. Figure 16A shows the apparent delay induced by the injection over this time span for both these wavefield components. As expected, direct arrival delays (blue circles) are zero above the aquifer unit, gradually increase across the Dammam, and achieve a maximum of approximately $89 \mu$ s for all receivers beneath the injection zone. All reflected arrivals recorded above the Dammam exhibit slightly more than double this delay $(194 \mu \mathrm{s})$ as they traverse the entire unit at a slightly different angle due to the lateral offset of the source. Figures 16B and 16C show an enlarged view of the basal reflection and direct events for both modeled surveys; the slight delay is visible but considerably less than the dominant cycle width of approximately $6.7 \mathrm{~ms}(150 \mathrm{~Hz})$.

Considering annual variations in near-surface conditions (e.g., soil moisture and water table depth), we expect that routinely obtaining the required travel-time accuracies (on the order of $\sim 10$ to $20 \mu \mathrm{s}$ ) using a traditional surface source (explosive or vibroseis) and wireline deployed downhole sensors will not be possible. Microwell vertical seismic profile (VSP) measurements based on permanently installed downhole sources and receivers deployed below the surface might be capable of detecting the pressure-mediated velocity variations; previous work by Meunier et al. (2001) has documented repeatability better than $50 \mu \mathrm{s}$. Likewise, cross-well measurements with stationary source and receiver arrays are capable of repeatability on this order as has been demonstrated by Silver et al. (2007). Unfortunately, both these approaches require secondary drilling and potentially costly semipermanent installations, two factors that may make their use impractical in the context of ASR activities. In light of this observation, the use of seismic methods at this site will likely be limited to obtaining static structural information useful in characterizing aquifer dimensions, extent, and heterogeneity for the purpose of siting ASR injection and recovery wells.

\section{Discussion}

By modeling the density-dependent coupled fluid flow and solute transport problem, we are able to produce an ensemble of possible flow scenarios given different hydrogeologic properties. This alone provides useful information regarding potential losses from the aquifer, buildup of pressure due to injection, and the ability to recover fresh water from various locations after a storage period that can help to guide the ASR site selection and injection/recovery parameters. In this study, we have strongly coupled the fluid flow and solute transport equations by providing relationships for fluid density and viscosity that vary dynamically with pressure and salinity. Although not studied here, fluid property changes with temperature can also be easily incorporated.

One important area of research involves the optimization of many injection and recovery wells; therefore, future work will focus on full 3D hydraulic models with multiple wells. This 3D geometry will also allow for the inclusion of regional groundwater flow effects, which have been neglected in this axisymmetric study. Regional flow on the order of $1 \mathrm{~m} /$ year should not dramatically change the results but should provide a more realistic fresh water bubble geometry and may also enhance mixing at the fresh water boundaries. Additionally, we would like to develop a dual-porosity model to more accurately represent the karst nature of the Dammam aquifer, where fractures may 


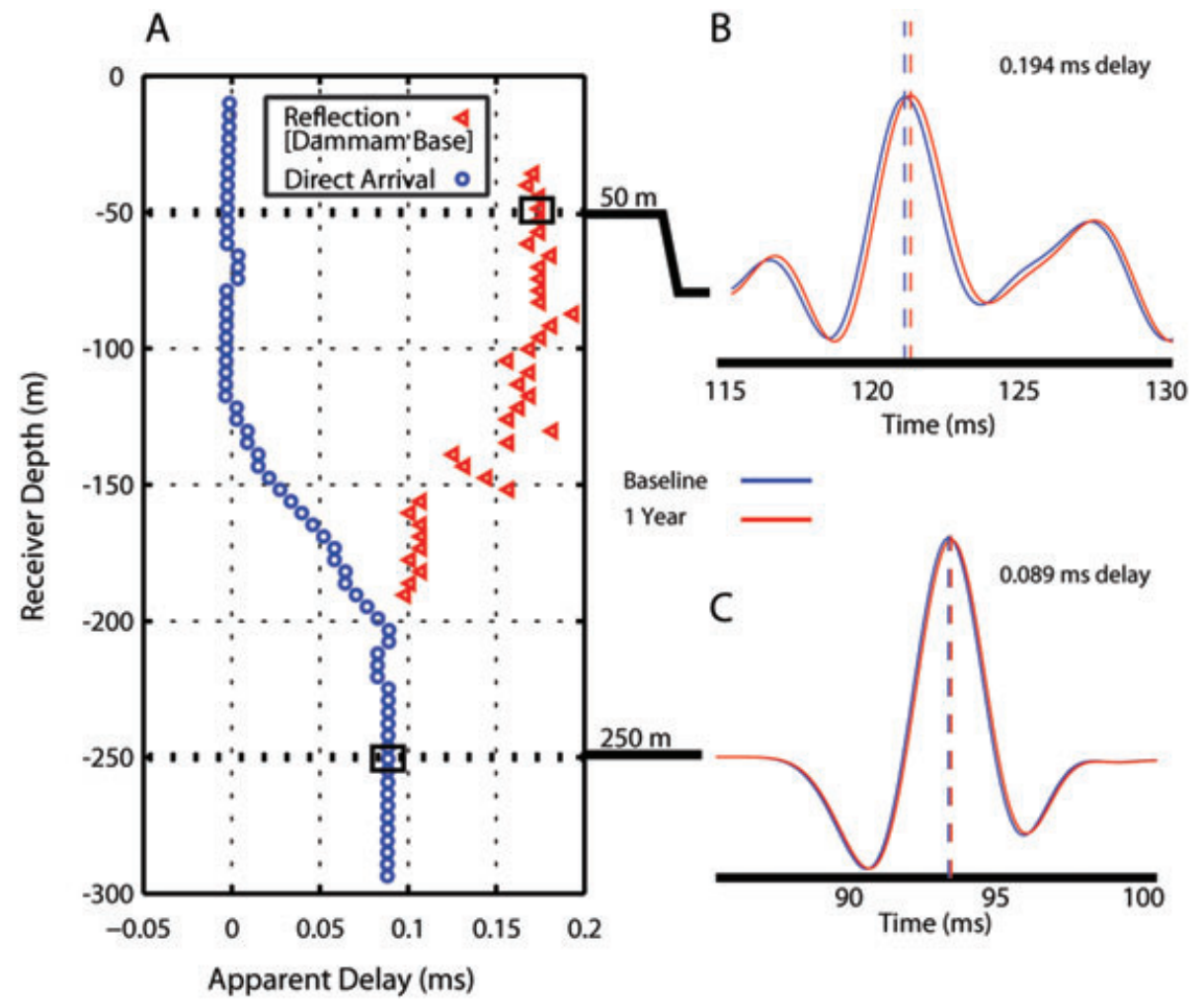

Figure 16. (A) Apparent delay induced by 1 year of injection for both direct (blue circle) and reflected (red triangle) wavefield components. An enlarged view of the basal reflection (B) and direct events (C) for both modeled surveys highlights the small delays due to injection.

play a significant role in fluid transport and rate-limited mass transfer (e.g., Culkin et al. 2008; Singha et al. 2007).

Geophysical methods represent a viable means for monitoring the various phases of an ASR project, although it is important to understand the expected response to different injection and recovery scenarios. This information will play an important role in the determination of which geophysical methods should be deployed, as well as survey design parameters. We have attempted to maintain self-consistency throughout the modeling experiment by converting the fixed matrix and dynamic fluid properties to bulk geophysical properties through various rock physics relationships. Site-specific information to improve the calibration of these relationships should be incorporated wherever possible.

One general observation regarding the differences between the electrical/electromagnetic and seismic methods is that they are sensitive to different components of the flow and solute transport model. The seismic response is mainly sensitive to changes in effective stress due to pore pressure changes and is therefore primarily influenced by diffusion of pressure into the aquifer governed by the fluid mass transport equation. The electrical/electromagnetic response, however, is mainly controlled by salinity changes brought about by the advective flux of fresh water into the aquifer governed by the solute transport equation. These are complementary methods in that they can answer different questions regarding the state of the aquifer during an ASR project, although we have seen that seismic methods have relatively low sensitivity given the hydrogeologic setting of this particular study. Acquisition and coupled inversion of multiple (time-lapse) datatypes may provide greater insight into the transport and storage properties of the aquifer than individual methods.

There is clearly a limited response for the TEM and seismic methods, which is primarily brought about by the particular details of this case study. The two greatest challenges for this ASR study are (1) the relatively deep aquifer used for injection and (2) the fact that the aquifer is confined. Many other ASR studies involve shallower, unconfined aquifers where fluids replace air in the pore space, thereby making them a more substantial geophysical target.

\section{Conclusions}

The primary contribution of this modeling study is the development of an integrated hydrogeophysical methodology that can be applied to a wide variety of ASR systems and hydrogeologic settings. This work provides a framework for guiding decisions regarding the siting, operation, and monitoring of the project to ensure optimal recovery of the stored water. The particular details of this case study involving a relatively deep/confined aquifer in Kuwait present a challenge for geophysical monitoring methods, and highlight the need for careful consideration and design of monitoring strategies depending on the hydrogeologic scenario. 
There are several areas for future research and improvement on both the hydrogeologic and geophysical aspects of this study. On the hydrogeologic side, models should incorporate additional site-specific information such as layer topography and porosity-permeability relationships. A dual-porosity model should also be considered where fracture flow may play an important role in flow and solute transport behavior. Additionally, a fully 3D model will allow the incorporation of regional groundwater flow effects and the ability to study an array of injection and recovery wells. On the geophysical side, incorporating site-specific information to calibrate rock physics relationships is an important step toward achieving more accurate modeling results. Other controlled source electromagnetic methods, such as airborne EM, should also be investigated, particularly for monitoring large study areas. Future field investigations are also needed to confirm the feasibility of various geophysical methods for monitoring ASR.

Integrated hydrogeophysical inversion methods, which incorporate both hydrogeologic and geophysical datasets, will play an important role in the ability to resolve subsurface changes related to the ASR experiment. Information gained during the forward modeling analysis, such as presented in this study, can be used within the inverse process. For example, regularization strategies derived from the properties of the coupled flow and transport modeling may help to produce more meaningful hydrogeophysical inverse models.

\section{Acknowledgments}

This work was funded by the Kuwait-MIT Center for Natural Resources and the Environment, with support from the Kuwait Foundation for the Advancement of Science. We are grateful for valuable suggestions provided by reviewers Fred Day-Lewis, Paul Bedrosian, William Hutchings, Dave Hart, and Joe Hughes.

\section{Supporting Information}

Additional Supporting Information may be found in the online version of this article:

This includes a seismic rock physics model for carbonates at low effective stress levels that is used to derive the seismic modeling parameters in this study.

Please note: Wiley-Blackwell is not responsible for the content or functionality of any supporting information supplied by the authors. Any queries (other than missing material) should be directed to the corresponding author for the article.

\section{References}

Ackerer, P., A. Younes, and R. Mose. 1999. Modeling variable density flow and solute transport in porous medium: 1 . Numerical model and verification. Transport in Porous Media 35, no. 3: 345-373.
Al-Awadi, E.A., and A. Mukhopadhyay. 1995. Hydrogeology of the Dammam formation in Umm Gudair area, Kuwait. In International Conference on Water Resources Management in Arid Countries, Muscat, Sultanate of Oman.

Al-Awadi, E., A. Mukhopadhyay, and M.N. Al-Senafy. 1998. Geology and hydrogeology of the Dammam formation in Kuwait. Hydrogeology Journal 6, no. 2: 302-314.

Al-Otaibi, M., and A. Mukhopadhyay. 2005. Options for managing water resources in Kuwait. Arabian Journal for Science and Engineering 30, no. 2C: 55-68.

Al-Ruwaih, F., and H.O. Ali. 1986. Resistivity measurements for groundwater investigation in the Umm Al-Aish area of northern Kuwait. Journal of Hydrology 88, no. 1-2: 185-198.

Al-Senafy, M., and J. Abraham. 2004. Vulnerability of groundwater resources from agricultural activities in southern Kuwait. Agricultural Water Management 64, no. 1: 1-15.

Archie, G.E. 1942. The electrical resistivity $\log$ as an aid in determining some reservoir characteristics. Transactions of the American Institute of Mining, Metallurgical and Petroleum Engineers 146: 54-62.

Auken, E., L. Nebel, and K.I. Sørensen. 2002. EMMA: A geophysical training and education tool for electromagnetic modeling and analysis. Journal of Environmental and Engineering Geophysics 7: 57-68.

Auken, E., L. Pellerin, N.B. Christensen, and K. Sørensen. 2006. A survey of current trends in near-surface electrical and electromagnetic methods. Geophysics 71, no. 5: G249-G260.

Batzle, M., and Z.J. Wang. 1992. Seismic properties of pore fluids. Geophysics 57, no. 11: 1396-1408.

Bear, J. 1972. Dynamics of Fluids in Porous Media. New York: American Elsevier Pub. Co.

Bevc, D., and H.F. Morrison. 1991. Borehole-to-surface electrical-resistivity monitoring of a salt-water injection experiment. Geophysics 56, no. 6: 769-777.

Castagna, J.P., M.L. Batzle, and R.L. Eastwood. 1985. Relationships between compressional-wave and shear-wave velocities in clastic silicate rocks. Geophysics 50: 571-581.

Cerjan, C., D. Kosloff, R. Kosloff, and M. Reshef. 1985. A nonreflecting boundary condition for discrete acoustic and elastic wave equations. Geophysics 50, no. 4: 705-708.

Culkin, S.L., K. Singha, and F.D. Day-Lewis. 2008. Implications of rate-limited mass transfer for aquifer storage and recovery. Ground Water 46, no. 4: 591-605.

Dablain, M. 1986. The application of high-order differencing to the scalar wave equation. Geophysics 51, no. 1: 127-139.

Danielsen, J.E., E. Auken, F. Jørgensen, V. Søndergaard, and K.I. Sørensen. 2003. The application of the transient electromagnetic method in hydrogeophysical surveys. Journal of Applied Geophysics 53, no. 4: 181-198.

Darnet, M., A. Maineult, and G. Marquis. 2004. On the origins of self-potential (SP) anomalies induced by water injections into geothermal reservoirs. Geophysical Research Letters 31, no. 19: L19609.

Davis, K., Y. Li, and M. Batzle. 2008. Time-lapse gravity monitoring: a systematic 4D approach with application to aquifer storage and recovery. Geophysics 73, no. 6 : WA61-WA69.

Fitterman, D.V., and M.T. Stewart. 1986. Transient electromagnetic sounding for groundwater. Geophysics 51, no. 4: 995-1005.

Keller, G.V., and F.C. Frischknecht. 1966. Electrical Methods in Geophysical Prospecting. Oxford, UK: Pergamon Press.

Langevin, C.D. 2008. Modeling axisymmetric flow and transport. Ground Water 46, no. 4: 579-590.

Mavko, G., T. Mukerji, and J. Dvorkin. 1998. The Rock Physics Handbook: Tools for Seismic Analysis in Porous Media. Cambridge, UK: Cambridge University Press. 
Meunier, J., F. Huguet, and P. Meynier. 2001. Reservoir monitoring using permanent sources and vertical receiver antennae: the Cere-la-Ronde case study. The Leading Edge 6: 622-629.

Miller, C., P. Routh, P. Donaldson, Y.G. Li, and D. Oldenburg. 2006. Feasibility study of time-lapse controlled-source electromagnetics for the aquifer storage problem. SEG Summer Research Workshop on Hydrogeophysics, Vancouver, Canada.

Mukhopadhyay, A., and M. Al-Otaibi. 2002. Numerical simulation of freshwater storage in the Dammam formation, Kuwait. Arabian Journal for Science and Engineering 27, no. 2B: $127-150$.

Mukhopadhyay, A., J. Al-Sulaimi, E. Al-Awadi, and F. AlRuwaih. 1996. An overview of the tertiary geology and hydrogeology of the northern part of the Arabian Gulf region with special reference to Kuwait. Earth Science Reviews 40, no. 3-4: 259-295.

Mukhopadhyay, A., J. Al-Sulaimi, and A.A. Al-Sumait. 1998. Creation of potable water reserves in Kuwait through artifical recharge. In: Proceedings of the Third International Symposium on Artificial Recharge of Groundwater-TISAR98. Artificial Recharge of Groundwater, ed. J.H. Peters, 175-180. Rotterdam, Netherlands: A.A. Balkema.

Nabighian, M.N., and J.C. Macnae. 1991. Time domain electromagnetic prospecting methods. In: Electromagnetic Methods in Applied Geophysics. Application, vol. 2, ed. M.N. Nabighian. Tulsa, Oklahoma: Society of Exploration Geophysicists.

Nagel, N.B. 2001. Compaction and subsidence issues within the petroleum industry: from wilmington to ekofisk and beyond. Physics and Chemistry of the Earth, Part A: Solid Earth and Geodesy 26, no. 1-2: 3-14.
Omar, S.A., A. Al-Yacoubi, and Y. Senay. 1981. Geology and groundwater hydrology of the State of Kuwait. Journal of Arabian Peninsula Studies 1: 5-67.

Parra, J.O., C.L. Hackert, and M.W. Bennett. 2006. Permeability and porosity images based on P-wave surface seismic data: application to a south Florida aquifer. Water Resources Research 42, W02415.

Pyne, R.D.G. 1995. Groundwater Recharge and Wells: A Guide to Aquifer Storage Recovery. Boca Raton, Florida: Lewis Publishers.

Rubin, Y., and S.S. Hubbard, ed. 2005. Hydrogeophysics. Water Science and Technology Library; vol. 50. Dordrecht, Netherlands: Springer.

Shi, W. 1998. Advanced modeling and inversion techniques for three-dimensional geoelectrical surveys. Ph.D. thesis, Massachusetts Institute of Technology, Cambridge, Massachusetts.

Silver, P.G., T.M. Daley, F. Niu, and E.L. Majer. 2007. Active source monitoring of cross-well seismic travel time for stress-induced changes. Bulletin of the Seismological Society of America 97, no. 1B: 281-293.

Singha, K., F.D. Day-Lewis, and J.W. Lane Jr. 2007. Geoelectrical evidence of bicontinuum transport in groundwater. Geophysical Research Letters 34, L12401.

Ward, J.D., C.T. Simmons, and P.J. Dillon. 2007. A theoretical analysis of mixed convection in aquifer storage and recovery: how important are density effects? Journal of Hydrology 343, no. 3-4: 169-186.

Zhang, J., R.L. Mackie, and T.R. Madden. 1995. 3D resistivity forward modeling and inversion using conjugate gradients. Geophysics 60, no. 5: 1313-1325.

\section{Is this journal in your library?}

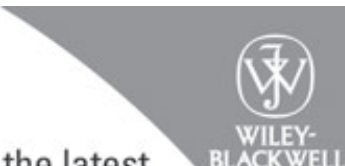

If not, recommend a subscription for your library and ensure the latest BLACKWELL research is accessible and readily available to you and your colleagues.

Two easy ways to recommend that your library subscribe:

1. Use our convenient online form:

www.blackwellpublishing.com/libraryreferral

2. Complete the form below and pass it along to your librarian.

\section{LIBRARY RECOMMENDATION FORM}

I have reviewed (journal title)

and believe it would be useful in our library.

Please consider my recommendation and subscribe to this journal.

Name:

Department:

Visit www.WileyInterscience.com for more information about the journal, including subscription prices.

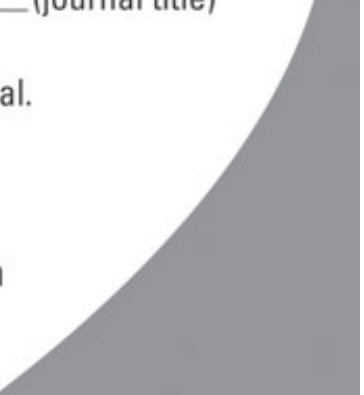




\section{Seismic rock-physics model for carbonates at low}

\section{effective stress levels}

When considering the seismic response from the Dammam aquifer, the first required component is a simple model relating porosity and stress state to frame moduli assuming a carbonate matrix. We explored two such relationships, one based on the empirical regression presented by Domenico (1984) and a second using the critical porosity model of Nur et al. (1998) calibrated to the ultrasonic measurements of Nur and Simmons (1969). Once frame properties for a given porosity/pressure state were

estimated, the effect of fluid changes were calculated using the low-frequency form of the Biot-Gassmann model, better known as Gassmann fluid substitution (Mavko et al., 1998).

Our development of a model mapping porosity/pressure to frame properties is hampered by both the absence of site calibration data and the paucity of experimental measurements on carbonates at low effective stress values ( $\leq 5 \mathrm{MPa}$ ) available within the open literature. This experimental gap is problematic for shallow aquifers, which are well within this pressure regime. Additionally, the pressure/velocity relationships for most rocks often exhibit a high gradient at low stresses due to the presence of open micro-cracks. Investigation of a large set of carbonate pressure versus $V_{P}$ measurements culled from publicly available datasets confirms highly variable frame properties due to variations in porosity, porosity type (vuggy vs. micro-porosity), and grain mineralology. More details on the dependence of carbonate elastic properties on calcite, aragonite, and dolomite fractions is available in Rafavich et al. (1984). The 
datasets we examined have at most only 2 data points below $5 \mathrm{MPa}$ making low pressure calculations somewhat unreliable.

For the limestones within our primary reservoir unit, we assume a matrix composed of $90 \%$ calcite and $10 \%$ quartz, which is within the range of values presented in Rafavich et al. (1984). Effective grain moduli are calculated using an average of the Hashin/Shtrikman upper and lower bounds as suggested by Mavko et al. (1998). Grain density is calculated using the arithmetic average of the component phases weighted by volume fraction. Pure calcite is assumed to have a bulk modulus $\left(K_{g}\right)$ of $70 \mathrm{GPa}$, a shear modulus $\left(\mu_{g}\right)$ of $29 \mathrm{GPa}$, and a density $\left(\rho_{g}\right)$ of $2710 \mathrm{~kg} \cdot \mathrm{m}^{-3}$. Pure quartz is assumed to have the following properties: $K_{g}=37.9 \mathrm{GPa}, \mu_{g}=44.3$ $\mathrm{GPa}$, and $\rho_{g}=2650 \mathrm{~kg} \cdot \mathrm{m}^{-3}$.

The first model examined is based on the empirical regressions presented in Domenico (1984). A model of the form

$$
V=\frac{1}{A+B \phi}
$$

is fit to a large suite of measurements including those documented by Pickett (1963). The regression coefficients $A$ and $B$ are tabulated for limestones at a variety of pressures for both $V_{P}$ and $V_{S}$. To estimate porosity/velocity relationships within our reservoir unit, we interpolate $A$ and $B$ to intermediate pressures using a low-order spline. Because the resulting empirical curves are based on water saturated measurements, dry frame properties are extracted using Gassmann's equation and effective grain moduli. 
The second model considered is based on the critical porosity model presented in Nur et al. (1998) and Mavko and Mukerji (1998). In the critical porosity model, the elastic moduli of a porous rock are assumed to be a Voigt average between the suspension state, which exists at the critical porosity, and the pure mineral properties (Mavko et al., 1998). While the critical porosity model provides a reasonable approach to building porosity/velocity relationships at high pressures where compliant cracks are closed, additional adaptation is required to include pressure dependence. Instead of using the pure mineral phase as the end-member of the Voigt average, we calibrate the model to a rock modulus measurement at a known porosity and a given pressure; this process provides a mechanism for incorporating pressure dependence into the critical porosity model. In our modeling experiments we assume a critical porosity of 0.6 as suggested by Mavko et al. (1998) and calibrate the models to the properties of Bedford limestone as documented in Nur and Simmons (1969).

Figure 1 shows the predictions of both models in terms of porosity/velocity at fixed pressure (A) and pressure/velocity at a fixed porosity (B). As can be seen in Figure $1 \mathrm{~B}$, the modified Domenico model exhibits higher $\mathrm{V}_{\mathrm{P}}$ gradients near low effective stress levels. This implies a higher sensitivity to variations in pore pressure during the aquifer injection process when compared to the modified critical porosity model. 
A

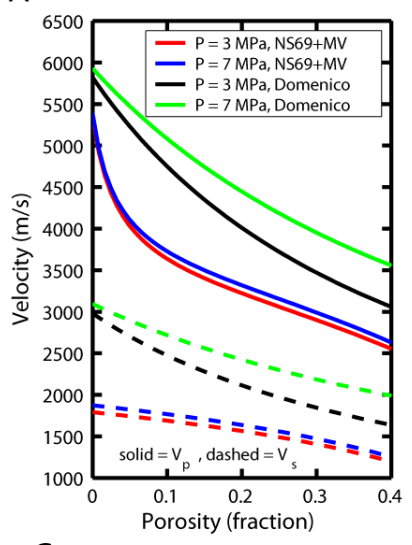

C

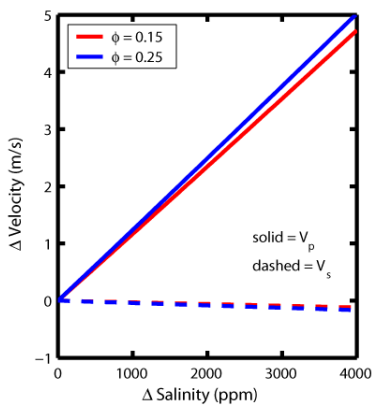

B

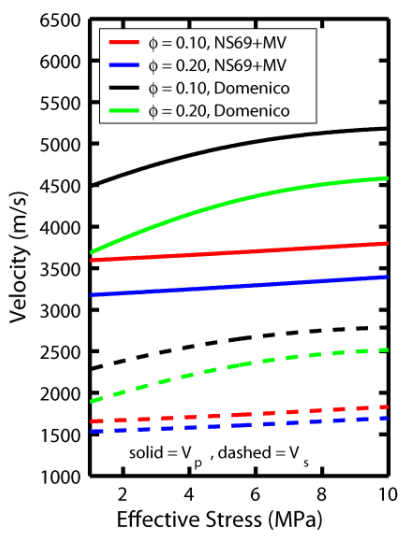

D

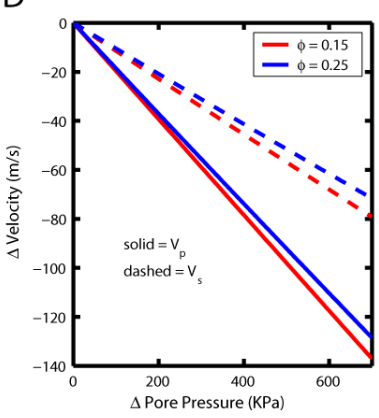

Figure 1: (A) and (B) compare the modified Domenico regression model and the critical porosity model calibrated to the Nur-Simmons dataset (NS69+MV). (A) Velocity as a function of porosity at two pressures (3 $\mathrm{MPa}, 7 \mathrm{MPa}$ ). (B) Velocity as a function of effective stress for two porosities $(0.1,0.2)$. (C) Sensitivity of seismic velocities to changes in pore fluid salinity and (D) pore pressure for two different porosities. Panel D uses the Domenico regression model. In all plots, solid lines denote $V_{P}$ while dashed lines indicate $V_{S}$.

The second component of our rock-physics model involves estimating the effects of changes in pore water salinity on the bulk seismic properties within the aquifer formation. Such an estimate relies on an accurate model of the way in which water's density and bulk modulus depends on salinity, temperature, and pressure; for this purpose we adopt the empirical model detailed in Batzle and Wang (1992). Because rock frame properties are calculated using the previously detailed empirical models, pore fluid effects are added using Gassmann fluid substitution.

Figure $1 \mathrm{C}$ and $\mathrm{D}$ shows the sensitivity of $\mathrm{V}_{\mathrm{P}}$ to changes in pore water salinity and pore pressure, respectively. In both plots the relationship between pressure, porosity, and frame moduli are calculated using the modified Domenico regression. Changing the brine salinity exerts a relatively weak effect on seismic velocity; in our case we 
observe a P-wave velocity increase on the order of $5 \mathrm{~m} \cdot \mathrm{s}^{-1}$ at $4000 \mathrm{ppm}$. When compared to a baseline velocity between 3000 and $5000 \mathrm{~m} \cdot \mathrm{s}^{-1}$, it seems highly unlikely that changes of this magnitude could be detected using either VSP or surface seismic geometries. In contrast, a change in pore pressure on the order of $700 \mathrm{kPa}$ can induce a decrease in $\mathrm{V}_{\mathrm{P}}$ of close to $150 \mathrm{~m} \cdot \mathrm{s}^{-1}$ with simultaneous reductions in $\mathrm{V}_{\mathrm{s}}$. This level of change might be detectable assuming highly repeatable experimental conditions, an adequate survey geometry, and a sufficient affected spatial domain.

\section{References}

Batzle, M. and Wang, Z.J., 1992. Seismic Properties of Pore Fluids. Geophysics, 57(11): 1396-1408.

Domenico, S.N., 1984. Rock lithology and porosity determination from shear and compressional wave velocity. Geophysics, 49: 1188-1195.

Mavko, G. and Mukerji, T., 1998. Comparison of the Krief and critical porosity models for prediction of porosity and Vp/Vs ratios. Geophysics, 63(3): 925927.

Mavko, G., Mukerji, T. and Dvorkin, J., 1998. The Rock Physics Handbook: Tools For Seismic Analysis In Porous Media. Cambridge University Press.

Nur, A., Mavko, G. and Galmudi, D., 1998. Critical porosity: A key to relating physical properties to porosity in rocks. The Leading Edge: 357-362.

Nur, A. and Simmons, G., 1969. The Effect of Saturation on Velocity in Low Porosity Rocks. Earth and Planetary Science Letters, 7: 183-193.

Pickett, G.R., 1963. Acoustic character logs and their applications in formation evaluation. Journal of Petroleum Technology: 659-677.

Rafavich, F., Kendall, C.H.S.C. and Todd, T.P., 1984. The relationship between acoustic properties and the petrographic character of carbonate rocks. Geophysics, 49: 1622-1636. 